PNL-10091

UC-2030

\title{
Some Theories of Dissolved Gas Release from Tank 241-SY-101
}

R. T. Allemann

September 1994

Prepared for

the U.S. Department of Energy

under Contract DE-AC06-76RLO 1830

Pacific Northwest Laboratory

Richland, Washington 99352 
, 


\section{DISCLAIMER}

This report was prepared as an account of work sponsored by an agency of the United States Government. Neither the United States Government nor any agency thereof, nor any of their employees, make any warranty, express or implied, or assumes any legal liability or responsibility for the accuracy, completeness, or usefulness of any information, apparatus, product, or process disclosed, or represents that its use would not infringe privately owned rights. Reference herein to any specific commercial product, process, or service by trade name, trademark, manufacturer, or otherwise does not necessarily constitute or imply its endorsement, recommendation, or favoring by the United States Government or any agency thereof. The views and opinions of authors expressed herein do not necessarily state or reflect those of the United States Government or any agency thereof. 


\section{DISCLAIMER}

Portions of this document may be illegible in electronic image products. Images are produced from the best available original document. 


\begin{abstract}
This report explains the ammonia release data to an order of magnitude agreement by the combination of three mechanisms of release: 1) bubble transport, 2) permeation/diffusion through the upper layers of the waste, and 3) diffusion/evaporation from freshly exposed liquid surfaces.

Bounded by these mechanisms, there is low danger of extremely high ammonia concentrations in the off gas. This condition would occur through some (unlikely) continuous replenishing of fresh liquid on the surface. This would not occur unless there were continuous energetic rollovers, which seem very unlikely given historical evidence, or by energetic mixing of the waste with more power than provided by the current mixing pump. Nitrous oxide is of low solubility in the waste and behaves similarly to hydrogen.
\end{abstract}




\section{,}




\section{Acknowledgments}

The author thanks Barry Gregory for the preparation of many of the graphic data reduction plots of the gas concentrations. Thanks also to the WHC staff who did the testing with 101-SY and produced the data, and particularly for the daily data graphs by Jeanne Lechelt and Leslie Tusler. Thanks also to John Nageley for the difficult task of editing this report. 
, 


\section{Contents}

Abstract $\ldots \ldots \ldots \ldots \ldots \ldots \ldots \ldots \ldots \ldots \ldots \ldots \ldots \ldots \ldots \ldots \ldots \ldots$

Acknowledgments $\ldots \ldots \ldots \ldots \ldots \ldots \ldots \ldots \ldots \ldots \ldots \ldots \ldots \ldots$

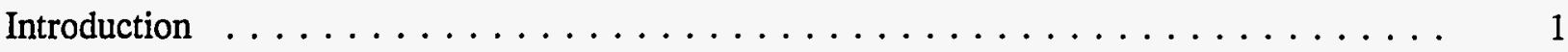

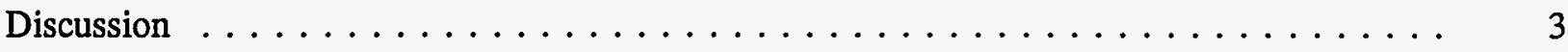

Proposed Model $\ldots \ldots \ldots \ldots \ldots \ldots \ldots \ldots \ldots \ldots \ldots \ldots \ldots \ldots \ldots \ldots$

Development of the Theory $\ldots \ldots \ldots \ldots \ldots \ldots \ldots \ldots \ldots \ldots \ldots$

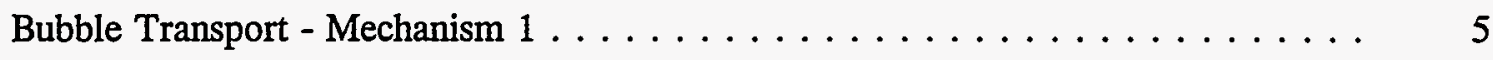

Permeation/Diffusion Through Upper Layers - Mechanism $2 \ldots \ldots \ldots$

Diffusion/Evaporation from Exposed Liquid Surfaces - Mechanism $3 \ldots \ldots$. . . . 14

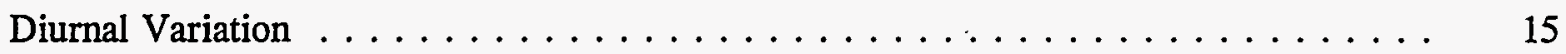

Nitrous Oxide Solubility $\ldots \ldots \ldots \ldots \ldots \ldots \ldots$

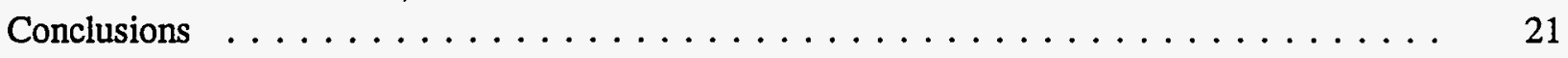

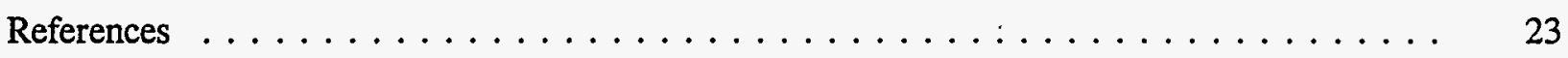

Appendix A - Estimation of Ammonia Concentration $\ldots \ldots \ldots \ldots \ldots$ A.1

Appendix B - Permeation of Ammonia Through Crust Layer $\ldots \ldots \ldots \ldots$. . . . . B.1

Appendix C - Diffusion of Ammonia from Fresh Liquid Surface $\ldots \ldots \ldots \ldots \ldots$ 


\section{Figures}

1 Gas Concentrations During Pump Burping Operations from July 25 to

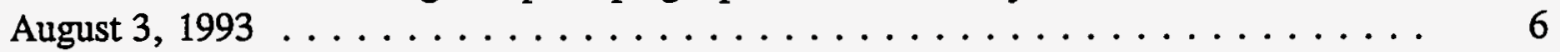

2 Normalized Gas Concentrations for November 15, $1993 \ldots \ldots \ldots \ldots$

3 Normalized Gas Concentrations for November $16,1993 \ldots \ldots \ldots \ldots \ldots$

4 Normalized Gas Concentrations for November 17, $1993 \ldots \ldots \ldots \ldots \ldots \ldots$

5 Normalized Gas Concentrations for November $19,1993 \ldots \ldots \ldots \ldots \ldots$

6 Normalized Gas Concentrations for December $9,1993 \ldots \ldots \ldots \ldots \ldots$

7 Normalized Gas Concentrations for December 13, $1993 \ldots \ldots \ldots \ldots$

8 Normalized Gas Concentrations for December 15, $1993 \ldots \ldots \ldots \ldots \ldots$

9 Normalized Gas Concentrations for December $17,1993 \ldots \ldots \ldots \ldots$

10 Normalized Gas Concentrations for December $20,1993 \ldots \ldots \ldots \ldots$

11a Ammonia and Nitrous Oxide Concentrations from November 30 to

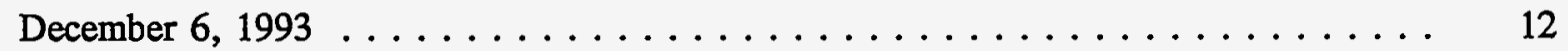

11b Hydrogen Concentrations from November 30 to December $6,1993 \ldots \ldots \ldots$

12a Ammonia and Nitrous Oxide Concentrations from May 20 to

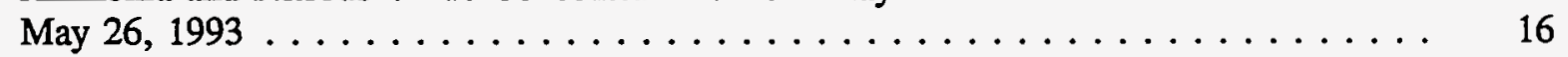

12b Hydrogen Concentrations from May 20 to May 26, $1993 \ldots \ldots \ldots \ldots$

13a Ammonia and Nitrous Oxide Concentrations from June 15 to

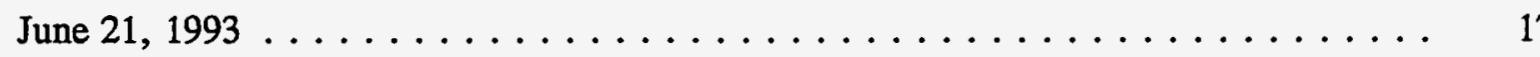

13b Hydrogen Concentrations from June 15 to June $21,1993 \ldots \ldots \ldots \ldots \ldots$

14a Ammonia and Nitrous Oxide Concentrations from April 29 to

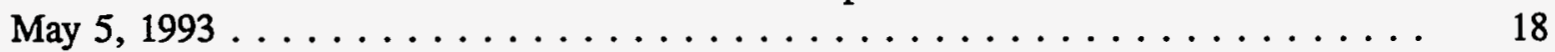

14b Hydrogen Concentrations from April 29 to May 5, $1993 \ldots \ldots \ldots \ldots$ 


\section{Introduction}

Concerns regarding the presence of ammonia in the off gas from tank 241-SY-101 have achieved prominence since the FTIR instrument was installed and on-line ammonia concentration measurements have become available. The concentrations were higher than had been anticipated from earlier estimates, and revisions to the Safety Assessment (Edwards 1993) for the mitigation tests were made to account for the possibility of higher ammonia releases. McDuffie (1993) ${ }^{(a)}$ has pointed out the observations and the possible implications of the ammonia content. Campbell (1993), ${ }^{(b)}$ a member of the Tank Waste Technical Advisory Panel, was concerned about the high concentration of the ammonia that may be dissolved in the waste but did not anticipate ammonia releases in higher concentrations than those observed in usual Gas Release Events (GREs). Kovach (1993) ${ }^{(\mathrm{c})}$ was concerned about making measurements of the ammonia to resolve the concentration issue. He felt that the ammonia might be a reaction product on the particle surfaces and might not therefore give usual vapor-liquid equilibrium concentrations. McDuffie reported ${ }^{(\mathfrak{d})}$ calculations to quantify conservatively the release rates of ammonia. This paper discusses some theories that may explain the ammonia behavior and give lower ammonia release rates from the wastes in 241-SY-101 than suggested by McDuffie's method. The implications of nitrous oxide solubility and release are also discussed.

(a) McDuffie, N. 1993. "Hanford Ammonia Concerns", Internal Letter, September 2, 1993. Westinghouse Hanford Company.

(b) Campbell, David O. 1993. "Possibility of High Ammonia content in SY-101," Letter to M. Kazimi, Tank Waste Advisory Panel, August 17, 1993, 102 Windham Road, Oak Ridge, TN 37830.

(c) Kovach, L. 1993. "Ammonia Solubility," cc:Mail Letters to Dave Campbell, September 1993.

(d) There were some corroborating calculations done by W. Kubic of Los Alamos National Laboratory, which were informally presented at a safety review meeting, Engineering Technology Center-1 Bldg., Richland, Washington, in October 1993. 
, 


\section{Discussion}

In McDuffie's (1993) method, the ammonia is calculated to leave the waste with a mass transport rate limited by the gas phase mass transport coefficient. This gives a conservative but unrealistically high value for the ammonia concentrations and duration of release. For example, he shows that a continuously exposed liquid surface on top of the waste would produce an ammonia concentration increasing toward $2.5 \%$ in two hours. McDuffie proposes that for safety purposes vigorous mixing should be assumed.

However, the actual data for rollovers do not continue to increase in this way. The tank data (as will be shown below) suggest that the ammonia rate is limited by the liquid side diffusion and by the diffusion through the "crust and foam" layer at the top of the waste. McDuffie suggested that the reduction in surface transport could be brought about by carbon dioxide absorption from the air with attendant carbonate formation on the surface, but he did not quantify this idea. The use of the mixing pump so far has exposed only a small amount of fresh liquid to the dome space; pump mixing would have to be extensive before fresh liquid would be exposed continuously at the surface. Computer model studies by Trent and Michener (1993) and physical modeling by Fort et al. (1993) of pump mixing of the tank have both shown that the mixing will be confined to the lower regions of the waste for a long period of time.

\section{Proposed Model}

It is recognized that the ammonia concentration in the waste is considerable. However, the actual in situ concentration has not been measured. ${ }^{(\mathrm{a})}$ It can be estimated (as shown in Appendix A) by use of data and with equilibrium-assumptions to be about $3 \mathrm{wt} \%$ (about 2.6 molar). ${ }^{\text {(b) }}$ This dissolved ammonia in 241-SY-101 behaves in a manner different from the relatively insoluble gases hydrogen, nitrogen, and nitrous oxide.

The release of ammonia is proposed to occur by three main mechanisms:

1. Bubble Transport - Ammonia is contained in bubbles of gas. The bubbles that have been observed coming from the surface of the waste during violent GREs have been associated with a drop in level and the release of hydrogen. The FTIR has shown that nitrous oxide is released at the same time as the hydrogen in roughly equal amounts and that ammonia comes off more

(a) Core C sample values reported by Herting et al. (1992) had widely varying NH3/NH4+ values. The highest values were in the range of $0.3 \%$. Herting reported lower values for the Core $\mathrm{E}$ samples (not referenced).

(b) This value is believed to be conservatively high, because a higher than average hydrostatic pressure is assumed and the "salting out" effect of the dissolved constituents may be underestimated by a factor of 3 to 5 . With the recalibration of the FTIR giving $40 \%$ more ammonia, the reduction in ammonia concentration would be about 2 to 3.5 . This reduction in assumed concentration will require some modification to the theory of diffusion layer thickness, but the theory still gives an acceptable order of magnitude explanation of the ammonia behavior. 
rapidly at this time. Also, some of these bubbles are assumed to be released continuously, either from the sludge layer or from the convective layer, giving a quiescent period basal rate of hydrogen, nitrogen, and nitrous oxide release and some of the basal rate of ammonia release.

2. Permeation/diffusion through upper layers of waste - Ammonia that is dissolved in the liquid also diffuses through the conductive layer at the top of the waste. This layer is considered to be of higher overall void fraction and may be a spongy foam and dried salt. The ammonia that diffuses through this upper layer provides additional (perhaps the major fraction of) ammonia to the basal rate of ammonia release.

3. Diffusion/Evaporation from exposed liquid surfaces - When a large GRE occurs, fresh liquid is washed to the surface. This liquid has dissolved ammonia that evaporates to the dome space air by virtue of the ammonia vapor pressure. The ammonia diffuses directly to the dome space through the liquid and air boundary layers. This evaporation gives large additional amounts of ammonia release for a period after an event. It is probably the mechanism that gives additional ammonia release during water lancing because of dissolution into the water and the creation of convective wet surface as the water addition floats and opens wet surface.

Some examples of mechanisms that may contribute to ammonia release, but are neglected or not evaluated in this discussion, include:

- release of ammonia compounds

- solids that have different diffusion rates than ammonia but are measured in the samples of the tank outlet stream

- ammonia driving forces having to do with reactions with humidity

- losses to pipe walls

- concentration differences between liquid in the convective and non-convective layers and mass transfer from rising bubbles

- counter diffusion of carbon dioxide

- reaction to form new resistance to the diffusion of gases.

The theory explains and implies that the concentration of ammonia in a major GRE is different (higher) than the ammonia in the slurry growth gas. The growth gas is hydrogen containing gas that is retained in the tank, causing the liquid level to slowly rise until the gas is released during a rollover. The fraction of ammonia in the growth gas is probably not the same as occurs by the chemical/ radiolysis processes in the tank because ammonia is soluble. The dissolved ammonia is transported in the liquid and partially released by the violent rollovers in mechanism 3 and more steadily lost by mechanism 2. 


\section{Development of the Theory}

In order to quantify the various parts of the ammonia transport release paths and estimate the concentration of dissolved ammonia, some broad averages of the data and treatment of the data had to be made. Therefore, the quantification of the theory are order of magnitude estimates. Key assumptions that were made to allow some quantification of the effects are as follows:

- Hydrogen is insoluble. All hydrogen released from the tank reaches the waste surface in the form of a separate phase (bubbles).

- The bubbles carry other gases, nitrogen, and nitrous oxide (in constant ratio to hydrogen), ammonia, water vapor (depending on their vapor pressures), and other gases.

- The three gases, nitrogen, hydrogen, and nitrous oxide, have known measured/deduced volume ratios in the slurry growth gas.

- The bubbles are large enough to be at one atmosphere pressure as they reach the surface of the waste (negligible surface tension effects).

- The ammonia and water vapor pressures equilibrate to their vapor pressures in the bubbles.

- Nitrous oxide is essentially insoluble. This assumption can be adjusted in more detailed developments of this theory.

- The concentration of dissolved ammonia in the liquid waste is uniform. [A concentration in the nonconvective layer is to be deduced from the data and used to estimate ammonia release from the liquid (convective layer) by diffusion processes.]

- The recent recalibration of the FTIR suggests that the ammonia data can be adjusted higher, but this will probably not affect the time constants used in the development of these mechanisms.

- There is no mass transport with rising bubbles.

\section{Bubble Transport - Mechanism 1}

The basal rate of release of ammonia and hydrogen are at different levels as may be seen in Figure 1. Ammonia settles back to about $50 \mathrm{ppm}$ after the peaks caused by the pump bumping (tests) while hydrogen and nitrous oxide return to a level of about $20 \mathrm{ppm}$. For these small bump and test releases, if one considers only the increase in concentration above the basal level and normalizes the concentrations of the three gases relative to their respective peaks, it is seen in Figures 2 through 10 that the decay of the concentration of all three gases is generally close to the same for these small peaks. The offset in time is probably due to a mis-estimate of the peak concentrations (e.g., hydrogen about $10 \%$ low or N2O-NH3 about $10 \%$ high). Another possibility is an instrumentation response delay, but this would not explain the data in Figure 7 which shows a deviation in delay between the two gas measurements from the same instrument. 


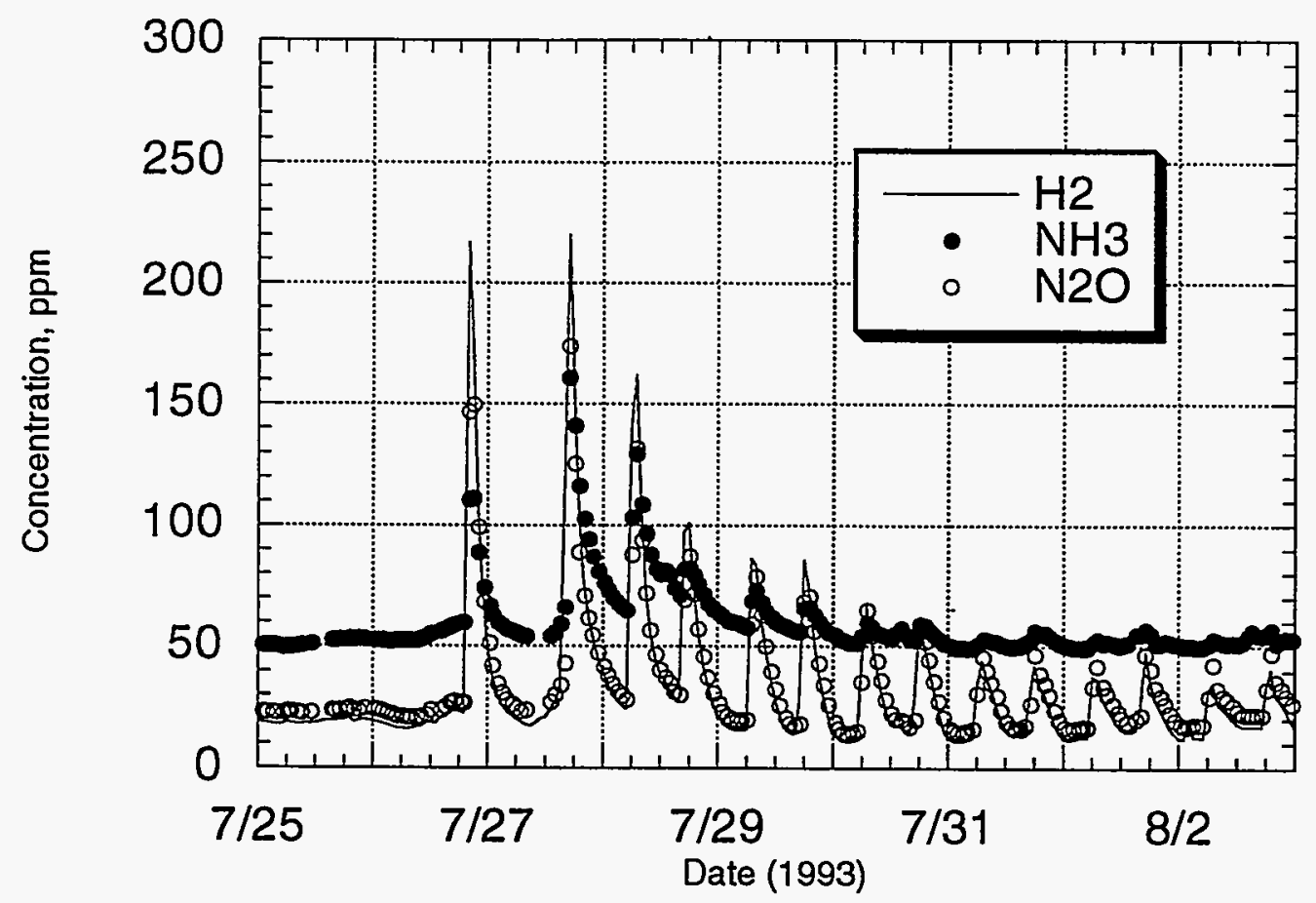

Figure 1. Gas Concentrations During Pump Bumping Operations from July 25 to August 3, 1993

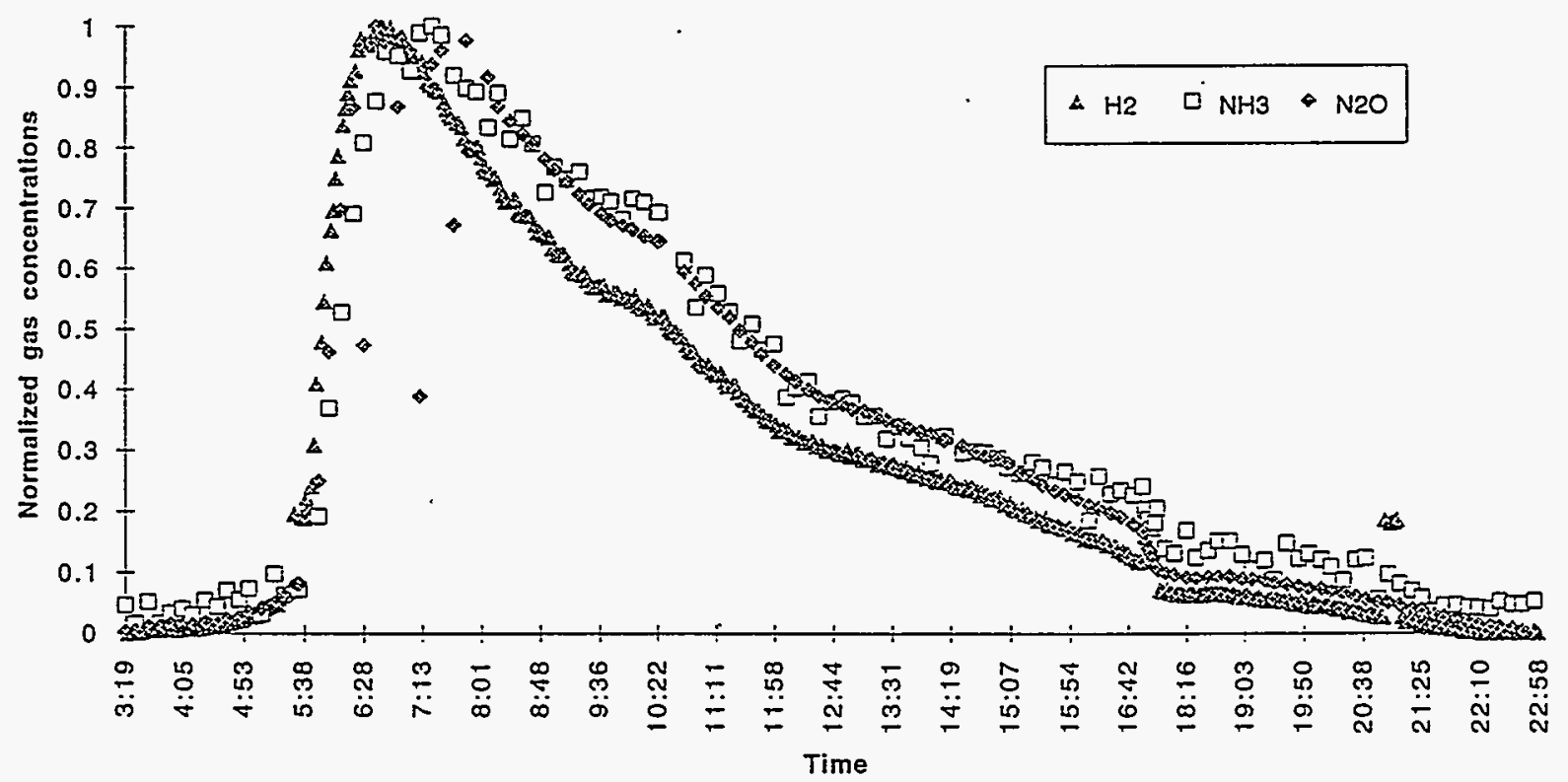

Figure 2. Normalized Gas Concentrations for November 15, 1993 


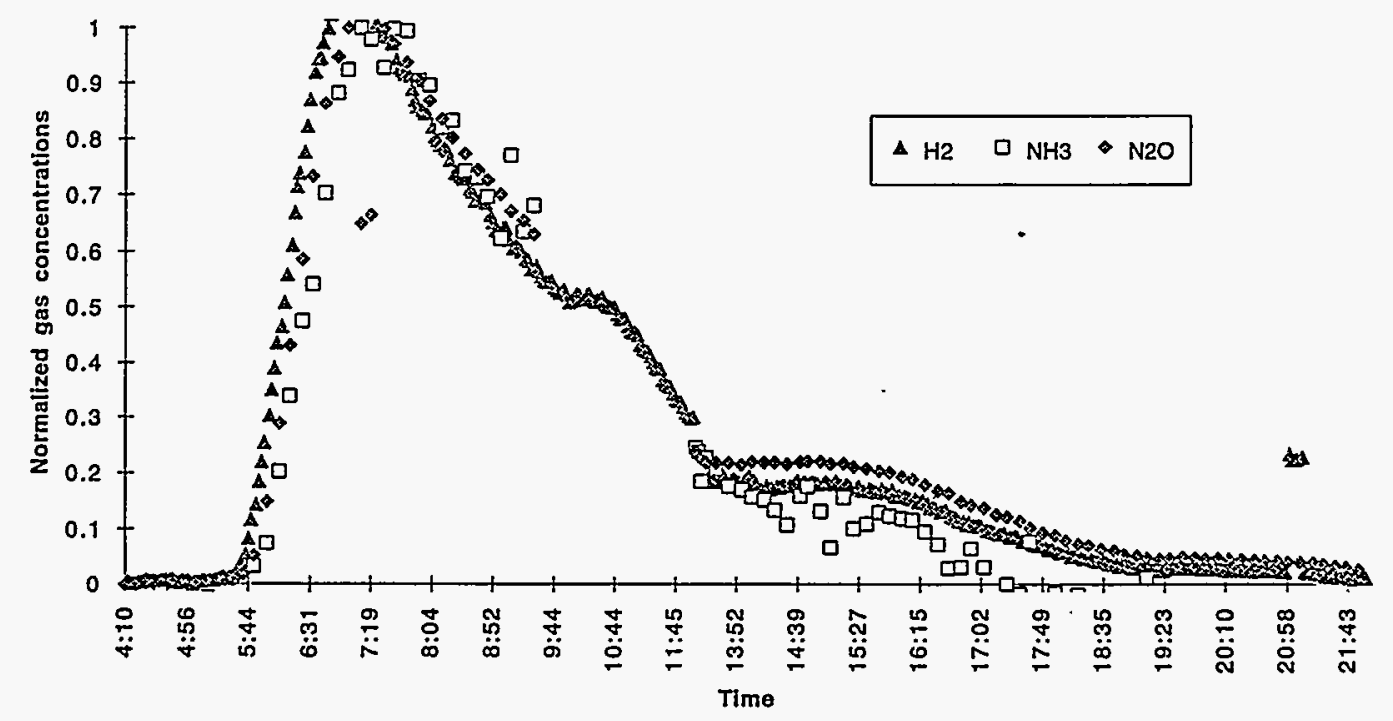

Figure 3. Normalized Gas Concentrations for November 16, 1993

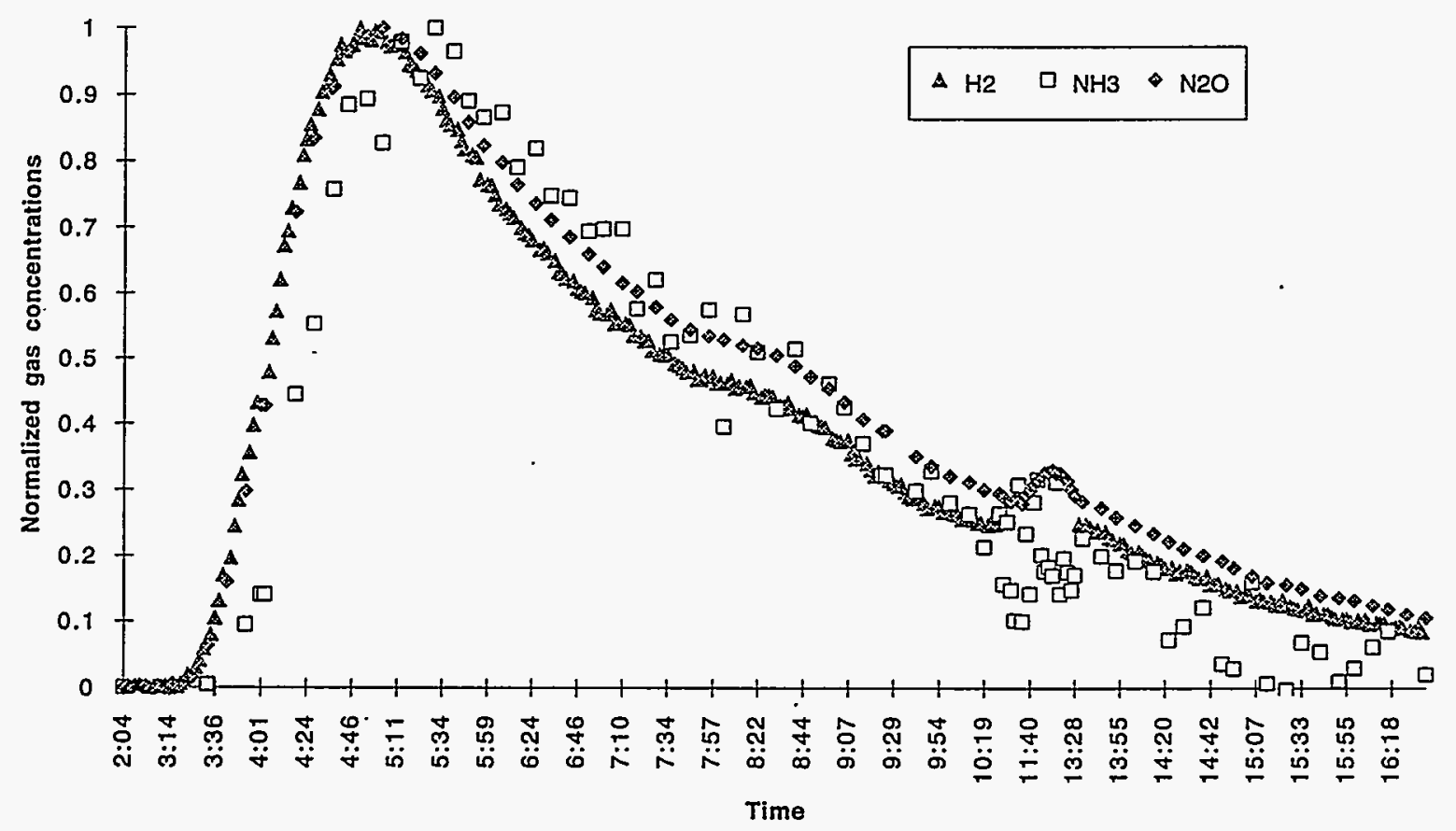

Figure 4. Normalized Gas Concentrations for November 17, 1993 

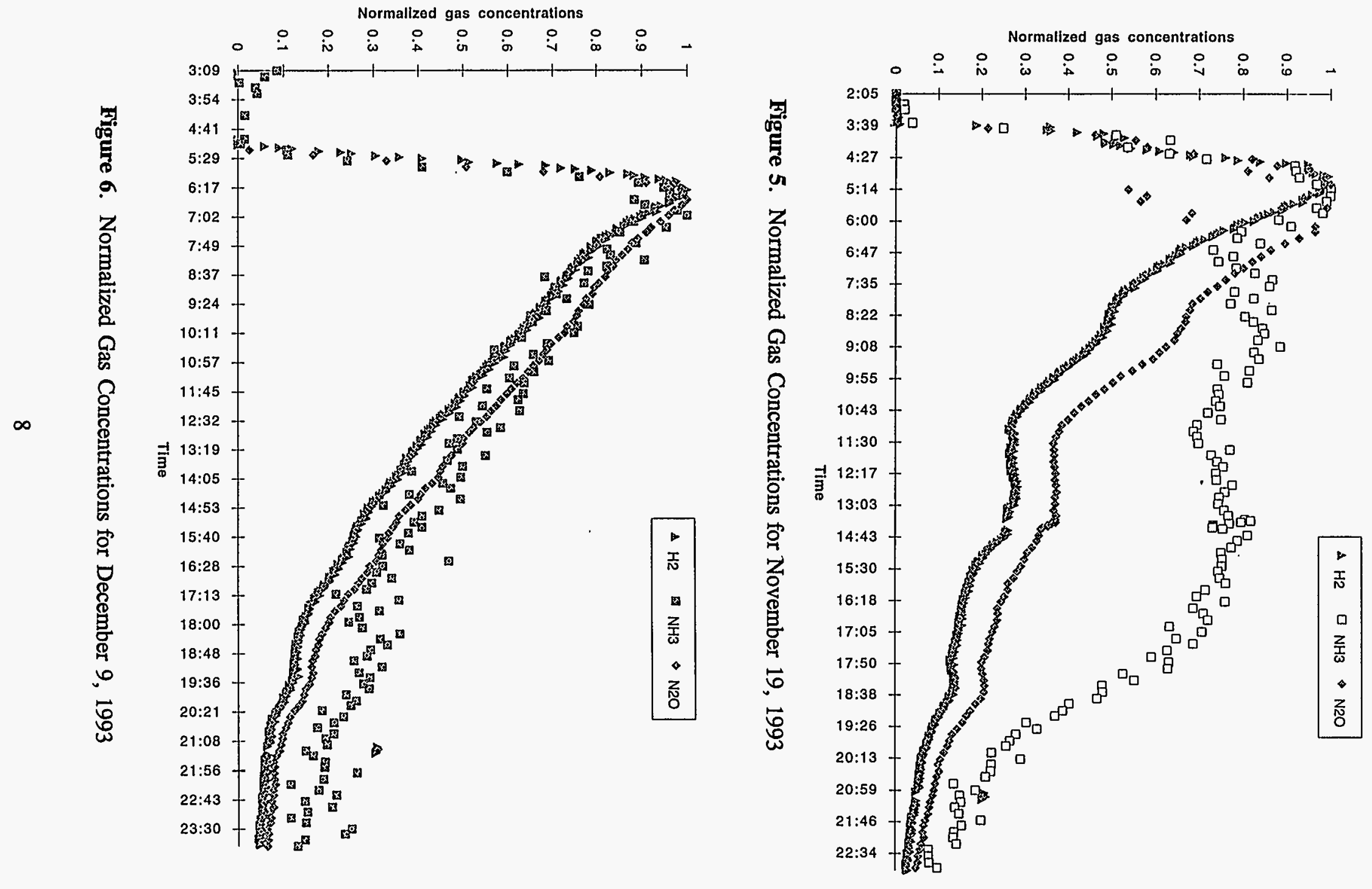

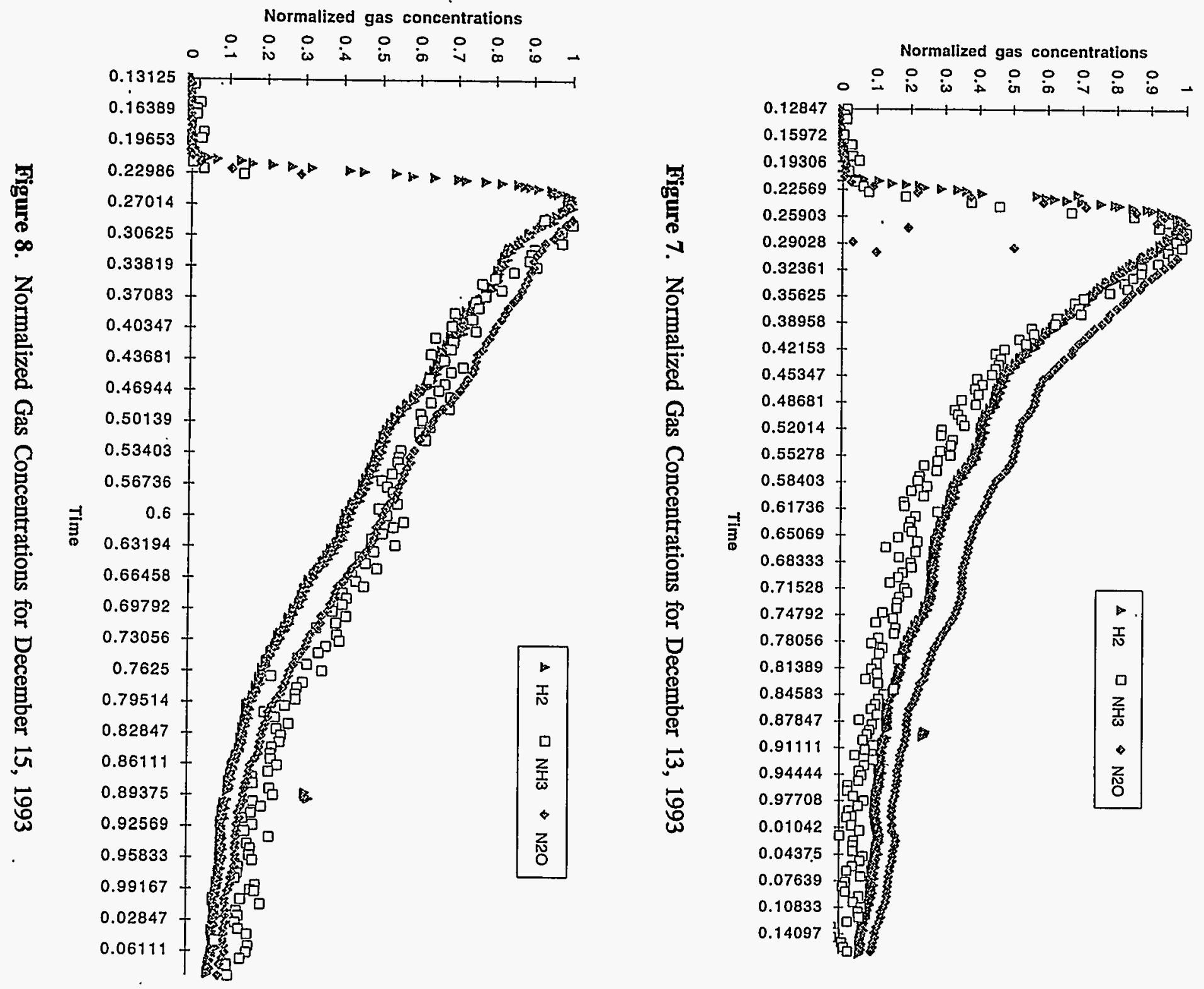

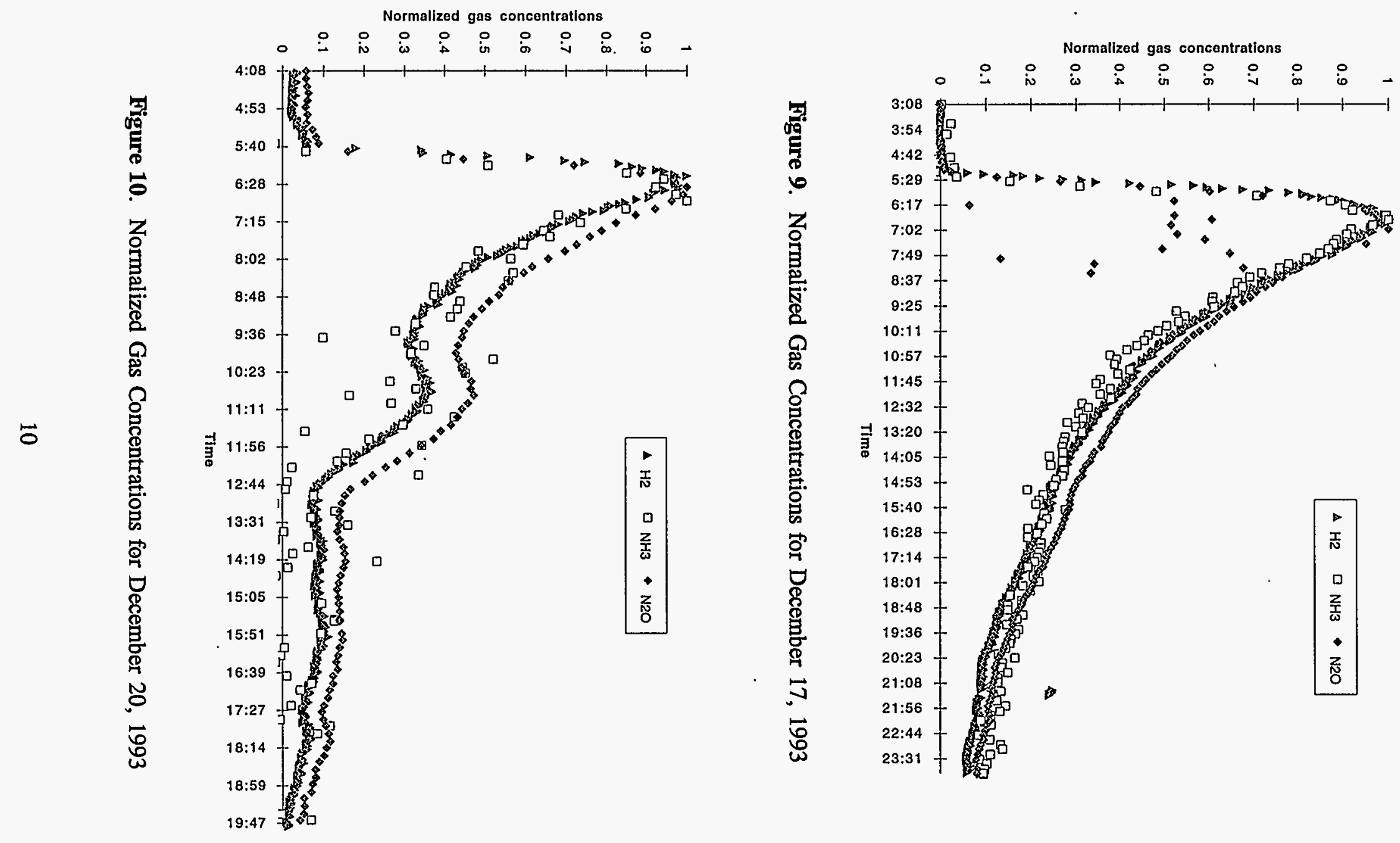
The time delays in most of the cases in Figures 2 through 10 probably are not due to an actual physical difference in the rate of concentration change between the three gases. The difference in ammonia in Figures 5 and 10 may be due to the differences in the mechanism and origin of the ammonia at small exposures of liquid surface. The long shoulder of ammonia concentration in Figure 5 was related to a high gage pressure and low temperature in the dome space and low vent flow; therefore, it was not a typical case. The data from the FTIR for ammonia and nitrous oxide are generally similar whereas the nitrous oxide behaves more like the hydrogen than the ammonia in this situation. The similarities in behavior for these three gases imply that the increased concentration and release of all three during small bump tests is due to the same mechanism, which is designated here as bubble transport. The actual concentration change in these small peaks then represents the concentrations in the level growth gas retained in the non-convective layer. This gas is presumed to be loosened from the bottom layer by the pump action. These bump releases tended to fade out after many bumps in the same direction. (See also Figure 1.)

After the Phase B test had been partly run, it was observed that the pump bumps, performed in the original $0^{\circ}$ orientation, produced a drop in both the nitrous oxide concentrations from the FTIR and the hydrogen concentrations from the gas chromatographs. Ammonia was less affected in these cases. This is shown in Figure 11a and $11 \mathrm{~b}$ for the bump of 12/03/93. The effective gas ratios are representative of an effect on mechanism 1 , bubble transport (see below). This is a relatively quiescent period (no large GREs) because the Phase B testing has reduced the level and gas content in the tank. The mechanism for this phenomenon is speculated to be the shifting of the bubbles in the upper regions by the fluid motion caused by the pump. This shift interrupts a delicate bubble gradient and release pattern that has been established over time. Michener $(1994)^{(a)}$ has done a TEMPEST simulation of this phenomenon that shows a slight downward as well as transverse velocity in the region near the top of the convective layer that occurs during the first minute of pump operation. In a few hours, the bubble gradient reestablishes and gives up not only the gas bubbles that were shifted over or down but also the new gas bubbles that had been generated during that period. This behavior causes a small peak in concentration equalling the loss in concentration that occurred first. This effect would be usually masked in Phase B testing by the large release caused by larger quantities of gas and larger bubbles that have been dislodged from the bottom by the jet penetrating into undisturbed regions of the nonconvective layer.

In Appendix A, the ratios of small bump release peaks were tabulated for several cases showing that the concentrations of nitrous oxide and hydrogen were almost the same and that ammonia was about 1/5 the concentration of the hydrogen. Considering the nonconvective layer pressure and the equilibrium condition in the gas bubbles, the concentration of the dissolved ammonia could be estimated (Appendix A).

The only measurements of ammonia that appear reliable are from the FTIR. Grab samples taken for mass spectrometer analysis are very sparse after June 1993. Although there have been some

(a) Michener, T. E. 1994. "TEMPEST calculations of Pump action in Partially Mixed tank," January 1994, Hydrogen Mitigation Program, MIT94:1719, Pacific Northwest Laboratory, Richland, Washington. 


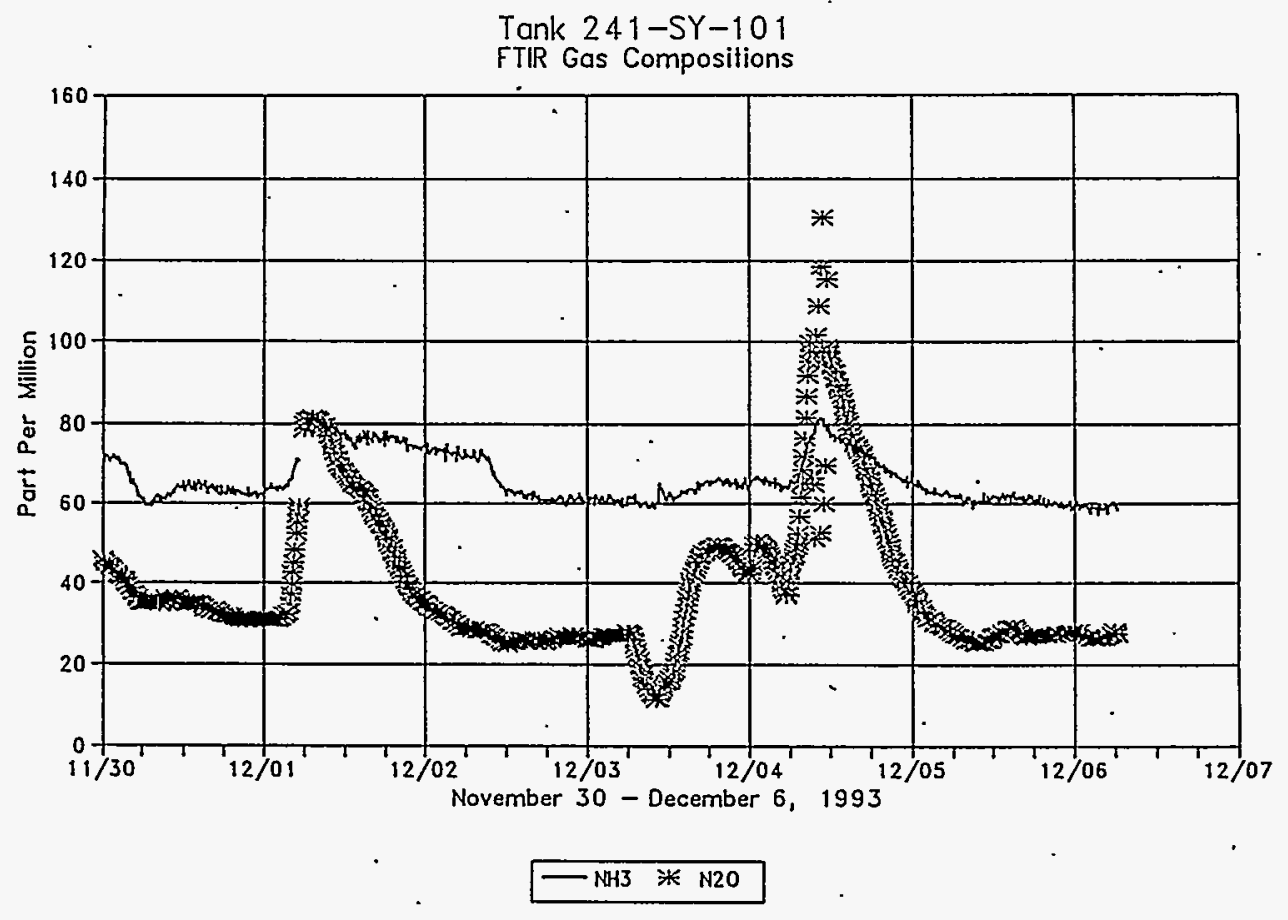

Figure 11a. Ammonia and Nitrous Oxide Concentrations from November 30 to December 6, 1993

Tank 241-SY-101

Gas Chromatograph 3 Hydrogen

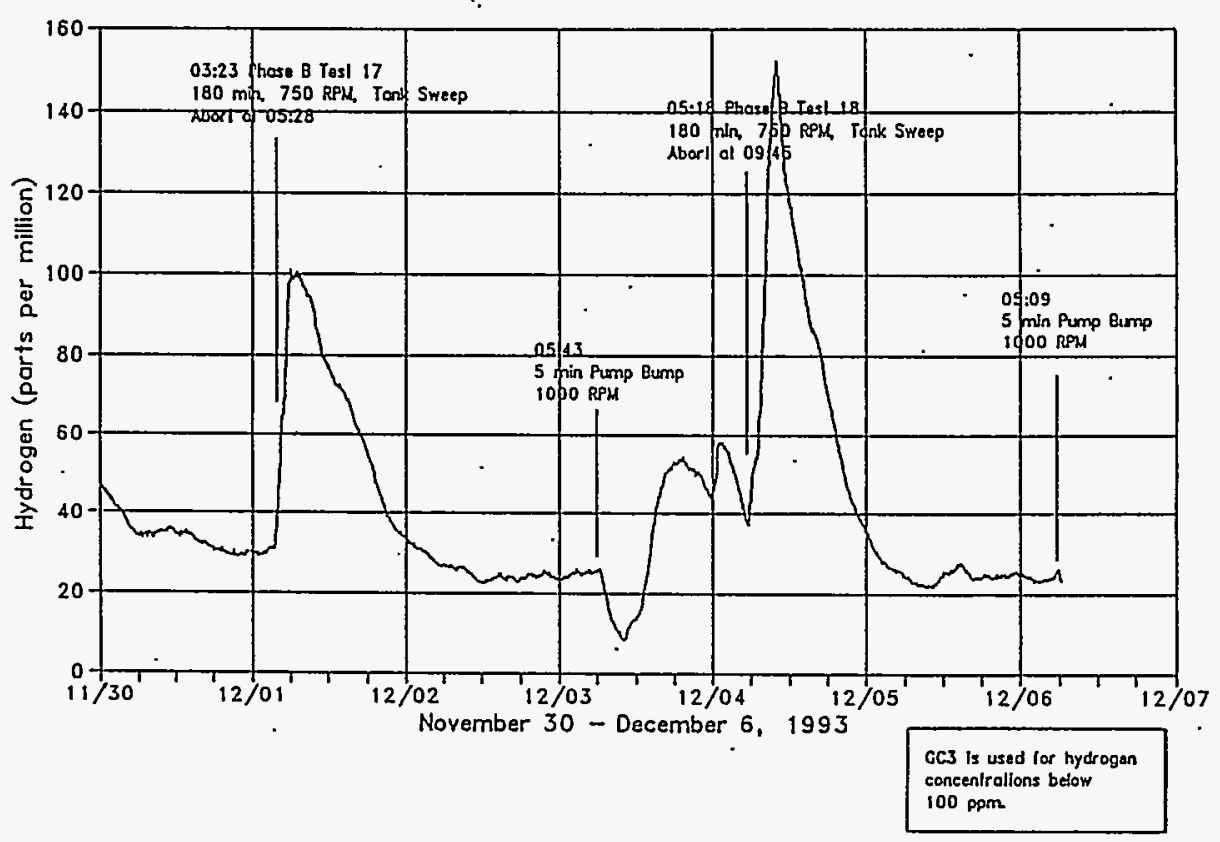

Figure 11b. Hydrogen Concentrations from November 30 to December 6, 1993 
calibration adjustments in the FTIR values that may alter the concentrations for the ammonia and nitrous oxide, the order of magnitude quantification of the theory will probably not be affected when the new values are given. ${ }^{(a)}$

\section{Permeation/Diffusion Through Upper Layers - Mechanism 2}

Some of the ammonia that is released is presumed to permeate the crust/foam layer that is floating as the top layer of the waste. This ammonia flux is the main component of the basal ammonia release. The quiescent (basal) release of ammonia is presumed to be made of two components:

1. One is associated with the basal bubble transport release of hydrogen. The hydrogen bubbles provide the basal hydrogen release and contain and release ammonia also. These bubbles may be formed in the convective layer and rise to be released, or they may be a relatively steady flux of bubbles coming off the nonconvective layer and rising through the convective layer and the crust/foam layer.

2. The other component of quiescent ammonia release is due to the steady permeation of ammonia through the crust foam layer from the dissolved ammonia in the liquid layer beneath. ${ }^{(b)}$

The basal ammonia release rate is therefore made up of the permeation rate plus about $1 / 5$ of the basal hydrogen rate. There is then about $45 \mathrm{ppm}-30 / 5 \mathrm{ppm} \approx 40 \mathrm{ppm}$ due to the permeation mechanism. Appendix $\mathrm{B}$ shows that the outflow concentration during the quiescent release of ammonia gives the rate of permeation through the 100 in. layer of crust and that this is consistent with estimated permeabilities of the porous media. The effective diffusivity is on the order of 0.03 times molecular diffusivity. This lower effective diffusivity can be explained by the effect of the diffusion through the foam and crust layer. Ratios are estimated in the literature to range from $10^{-3}$ to $10^{-2}$ for a discrete bimodal pore size model. Thus, it is quite likely that the reduced value needed to account for the calculated flux would be explained by the porous media theory. The actual (fairly slow) rate of ammonia transport through the foam/crust could be the result of the pore network effects, even when the crust is somewhat dry.

In a brief search, no significant information was found on the permeability of three-phase foam structures. It is expected that permeability of foam is also low so that with either type of floating layer the transport of the ammonia from the mixed conductive layer to the dome space would be significantly impeded. Thus, the resistance of the foam/crust layer moderates the transport phenomenon to a low rate during quiescent periods in the tank.

There is a barometric response of basal ammonia concentration to barometric pressure as illustrated by McDuffie (1993). The relation is on the order of $-1380( \pm 7 \%) \mathrm{ppm} / \mathrm{atm}$ [cf. Wise

(a) The recalibration suggests that $\mathrm{N}_{2} \mathrm{O}$ and $\mathrm{NH}_{3}$ values are higher than the values reported in this document. The ammonia is actually about $40 \%$ higher than used here, suggesting a higher partial pressure by a factor of about 1.4 .

(b) McDuffie suggests that transport through the foam may be enhanced by the Marongoni effect due to the use in surface tension as ammonia evaporates. This effect has not been considered in this paper. 
$\left.(1993)^{(a)}\right]$. This effect is larger than the effect on the hydrogen and nitrous oxide $(-433$

$( \pm 14 \%) \mathrm{ppm} / \mathrm{atm})$ concentrations; it also suggests that the pressure is affecting mechanism 2 or perhaps 3 more than mechanism 1 . This sensitivity of ammonia basal rate to pressure cannot be explained by a diffusivity driving force change; this can be shown to account for only $10-25 \%$ of the observed change. In addition, the back pressure of ammonia is already extremely low compared to the calculated vapor pressure in the liquid. It could be suggested that the changes in barometric pressure tend to physically move, compress, or knead the foam layer, which might have a relatively large effect on the diffusivity of that layer. The changes in diffusivity of the foam by this mechanical action are expected to be large when compared to the diffusivity of a stagnant foam or pore matrix. This mechanism suggests that the concentration would follow the slope of pressure changes rather than the actual value (as it seems to do). This effect has not been quantified and is not yet explained by this theory so needs further study.

\section{Diffusion/Evaporation from Exposed Liquid Surfaces - Mechanism 3}

The third mechanism of ammonia release is believed to be by diffusion of ammonia from fresh liquid exposed to the dome space in the course of large GREs or when visible motion and liquid movement occurs at the surface of the waste. This phenomena is also believed to be responsible for the ammonia release when water sluicing or lancing operations have been performed in 241-SY-101. Appendix $\mathrm{C}$ shows that the amount of ammonia that is released during some events in which waste surface motion could be seen on the in-tank video is of the same order of magnitude that would be present in a thin boundary layer of newly formed liquid surface that does not subsequently mix. The formation of the boundary layer and diffusion of the ammonia from the layer occurs rapidly and gives a short pulse of ammonia that behaves and decays away in the dome space with a time constant partially dependent on the venting rate. For example, a 65 min dome space time constant results in a lag effect that leaves the observed 380 min ammonia time constant, mainly governed by a boundary layer formation constant of 319 min-1. (See Appendix C.)

There was an observation that the ammonia began to increase in concentration before the main part of the GRE began in event I, on June 26, 1993, and was also associated with a decreasing barometric pressure (McDuffie 1993). This effect on ammonia also suggests that a different mechanism of release is involved than for the hydrogen. This behavior may be attributed to mechanism 2 , that of the diffusion through the crust/foam, which is changed as the pressure drops or as small cracks are created and liquid surface is exposed to the dome space as in mechanism 3 . These effects might have come about because of slight expansion and upward motion of gas in the $\mathrm{N}-\mathrm{C}$ layer that began to physically move the crust and affect the rate of ammonia evaporation without influencing the bubble transport mechanism. As discussed in Appendix A, there is a much larger amount of ammonia released relative to hydrogen when surface motion of the crust has been observed.

The fact that the ammonia ceases to come off new liquid surface has been suggested to be due to the formation of carbonate crust. However, it can more easily be explained by the liquid boundary

(a) Wise, B. M. 1993. "Ammonia vs. Barometric Pressure," Presentation to Tank Waste Advisory Panel, Richland, June 23, 1993, Minutes of the Tank Waste Science Panel Meeting, June 21-23, 1993, U.S. Department of Energy, Richland, Washington. 
layer theory on the basis that the material is no longer mixing and that it now behaves in a viscous manner. The carbonate crust theory might not explain the decay away of ammonia concentration after a water addition.

It would take a great effort to mix fresh waste liquid to the surface by pump action. In fact, it is somewhat unlikely (from experimental and theoretical hydraulic studies) that the pump action will reach the surface for the size and velocity of the jets being used. Thus the material in the tank tends to be "safe" in this regard. It self-limits the amount of ammonia that can be released, and the maximum would be produced in a major rollover mostly by mechanism 3 . Control of the tank by pumping should eliminate large rollovers, and the tank waste material properties will limit the rate of ammonia release on a day-to-day basis. This knowledge of tank behavior should be helpful in deciding on future operations in the tank.

\section{Diurnal Variation}

It has be observed that there is a daily variation in the concentrations of the three measured gases, $\mathrm{H}_{2}, \mathrm{~N}_{2} \mathrm{O}$, and $\mathrm{NH}_{3}$, with the concentrations increasing in the afternoon almost every day. Figures $12 \mathrm{a}$ and $12 \mathrm{~b}$ show this effect on the quiescent period about two months after the previous GRE. On April 30 and May 1, the diurnal rise of the hydrogen and nitrous oxide was about the same and it was less for ammonia. In this case, it appears that the cause of the diurnal variation is affecting mainly mechanism 1 as evidenced by the relatively small change in the ammonia concentration. Three weeks later, however, the diurnal effect on amimonia was greater than for the other two gases as shown in Figures 13a and 13b. By the middle of June, shortly before the GRE of June 26, 1993, (Event 1 ), the ammonia diurnal variation had become even more pronounced as seen in Figures 14a and 14b. Associated with this increase in diurnal sensitivity, the general concentration of ammonia rose as the June $26 \mathrm{GRE}$ approached, as discussed above. This change in sensitivity of ammonia to the diurnal effect is further evidence of the difference in the mechanisms of the ammonia release from the other two gases.

The reason for the diurnal variation in concentration is not due to the temperature caused change in flow rate. Hudson (1993) ${ }^{(a)}$ showed that the flow rate changes were too small to account for the variations in concentrations. Therefore, the diurnal concentration variations represented real changes in the rates that the gases were coming from the tank. Hudson is still working on the data to find important correlations. It is speculated that, because there is a correlation with relative humidity, the diurnal changes affect the way that the bubble released gases pass through the upper layer of dry crust. Humidity may affect the pore size or membrane thickness in the porous structure or the rate at which bubbles break at the interface and thus influence the rate at which the gases diffuse through the uppermost layer. The increased sensitivity of ammonia to diurnal variation when the tank level approaches a GRE condition may be due to increasing effects of mechanism 3-micro cracks exposing more saturated liquid to paths through the crust which are then influenced by the humidity in the same manner as the mechanism 1 of hydrogen and nitrous oxide. More micro cracks may come from the

(a) Hudson, J. D. 1993. "Effect of Vent Flow Rate on Concentration" in Monthly Report, Flammable Gas Safety Program, September 1993, FGP93:105, Pacific Northwest Laboratory, Richland, Washington. 
Tank 101-SY Hydrogen Mitigation Test

FTIR Gas Compositions

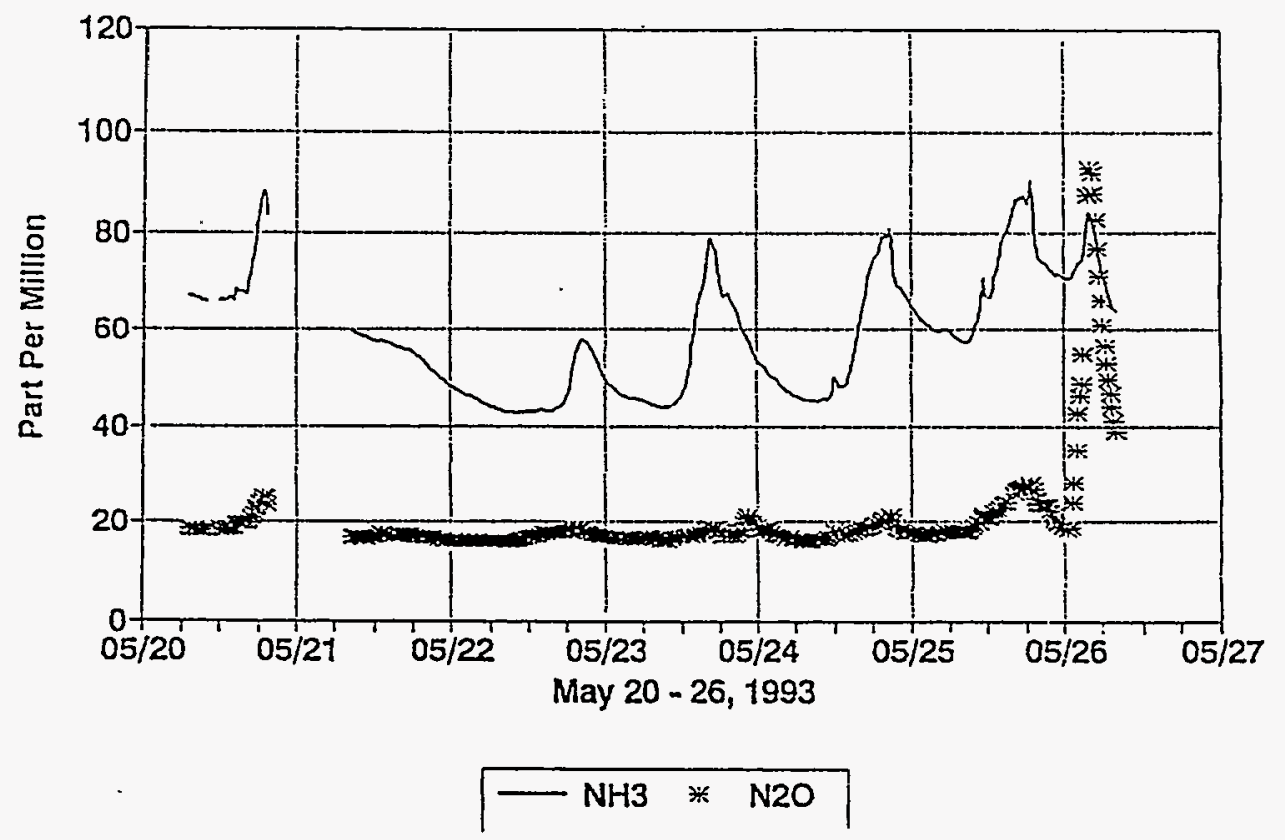

Figure 12a. Ammonia and Nitrous Oxide Concentrations from May 20 to May 26, 1993

Tank 101-SY Hydrogen Mitigation Test

Normalized Gas Chromatograph

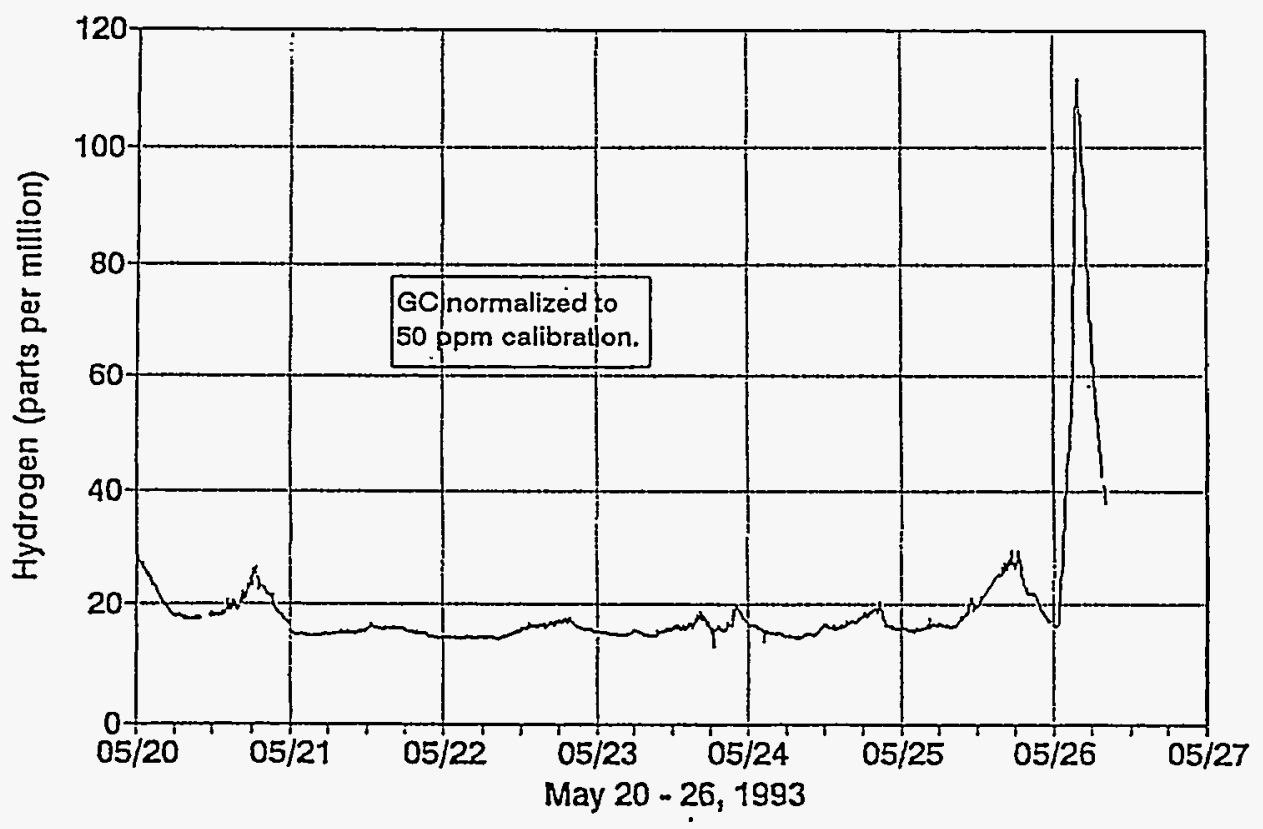

Figure 12b. Hydrogen Concentrations from May 20 to May 26, 1993 
Tank 241-SY-101

FTIR Gas Compositions

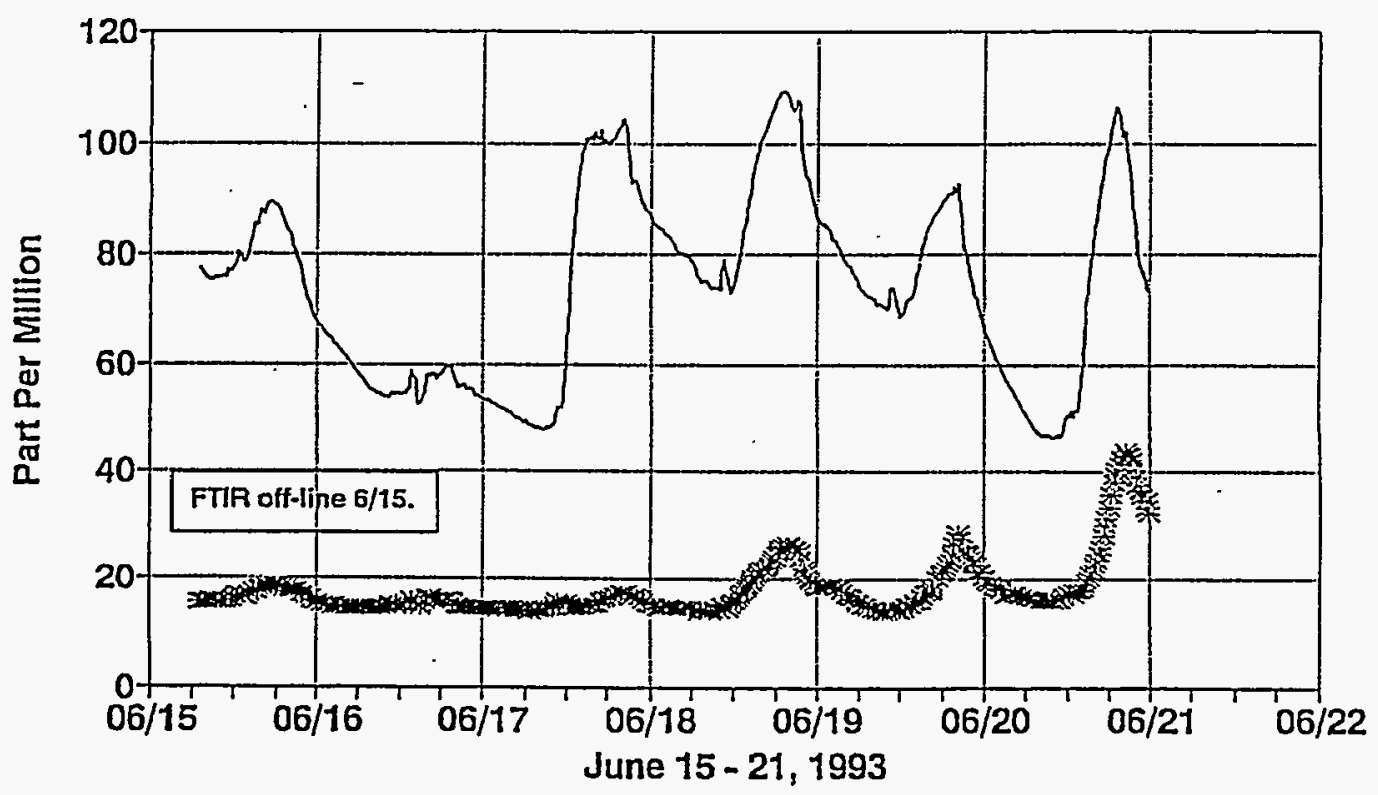

$\mathrm{NH3} * \mathrm{~N} 2 \mathrm{O}$

Figure 13a. Ammonia and Nitrous Oxide Concentrations from June 15 to June 21, 1993

Tank 241-SY-101

Normalized Gas Chromatograph

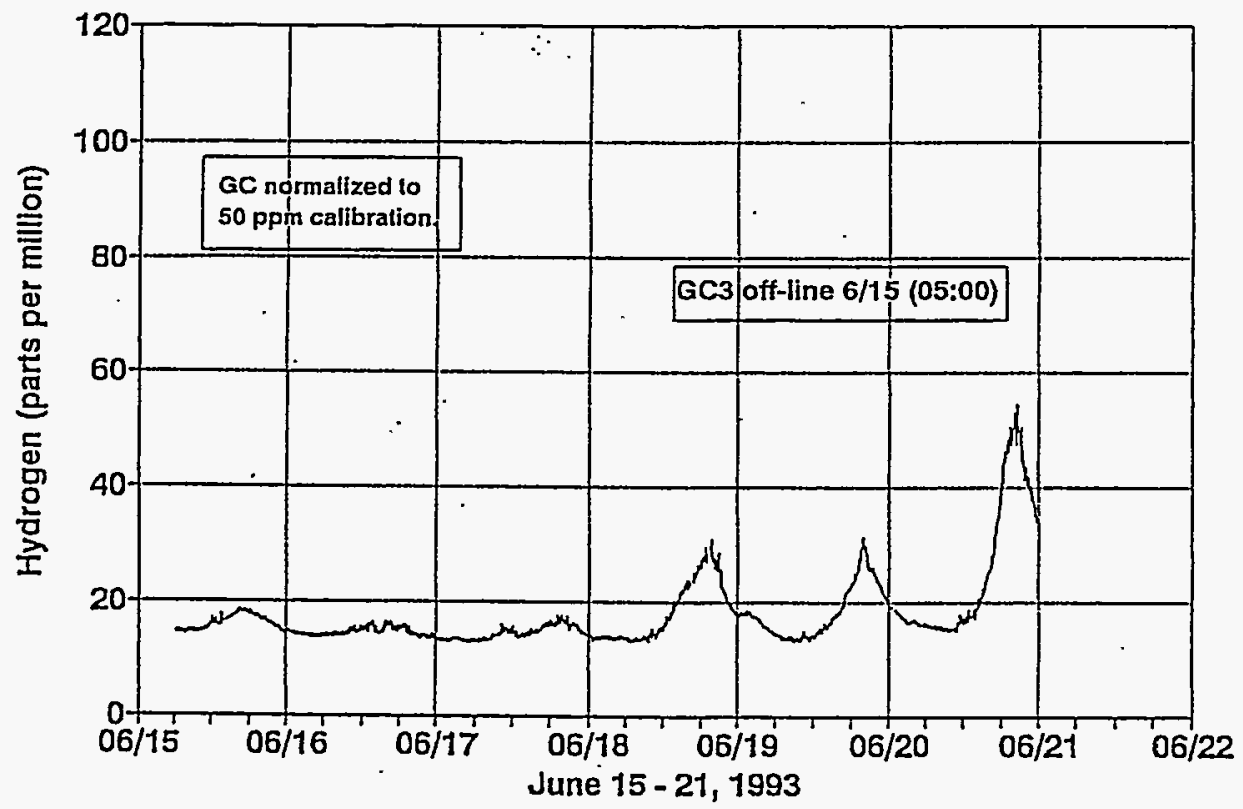

Figure 13b. Hydrogen Concentrations from June 15 to June 21, 1993 
Tank 101-SY Hydrogen Mitigation Test

FTIR Gas Compositions

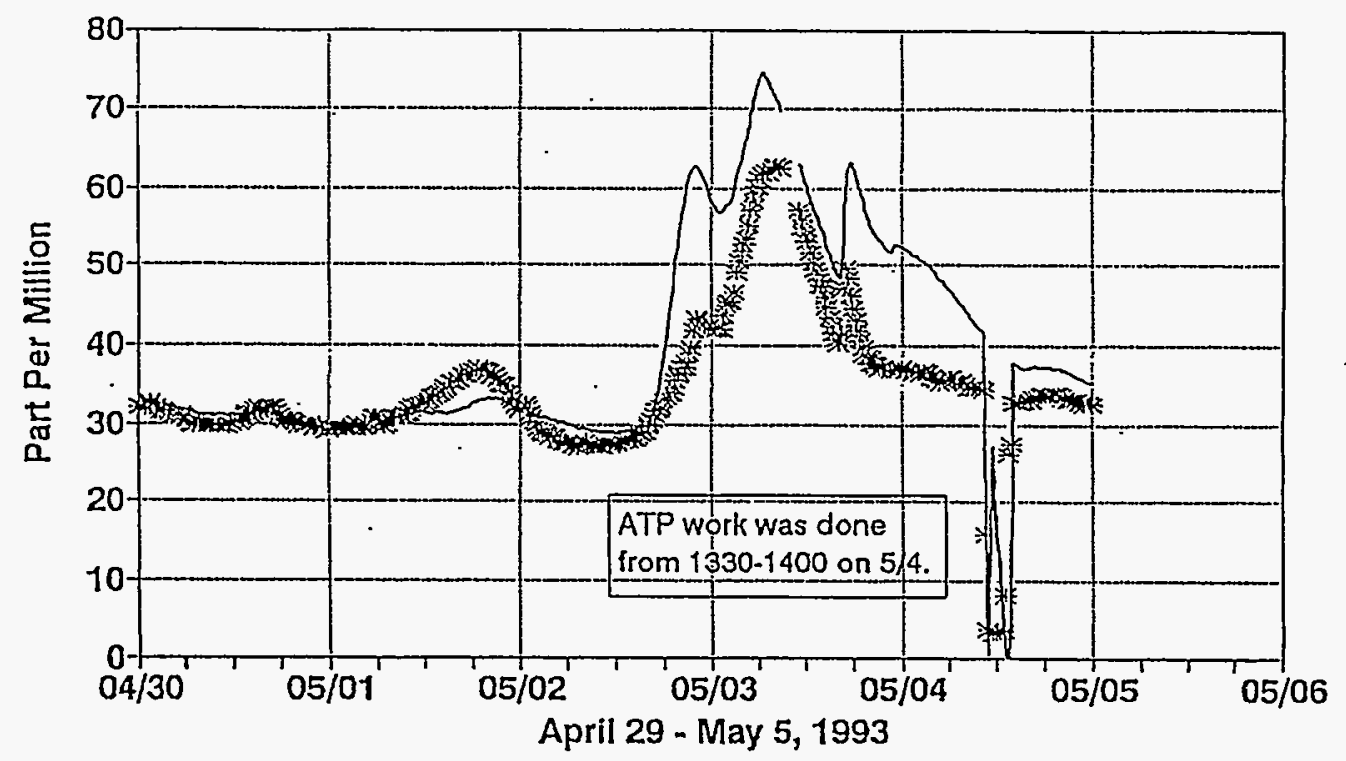

$\mathrm{NH3}$ * $\mathrm{N2O}$

Figure 14a. Ammonia and Nitrous Oxide Concentrations from April 29 to May 5, 1993

Tank 101-SY Hydrogen Mitigation Test Normalized Gas Chromatograph

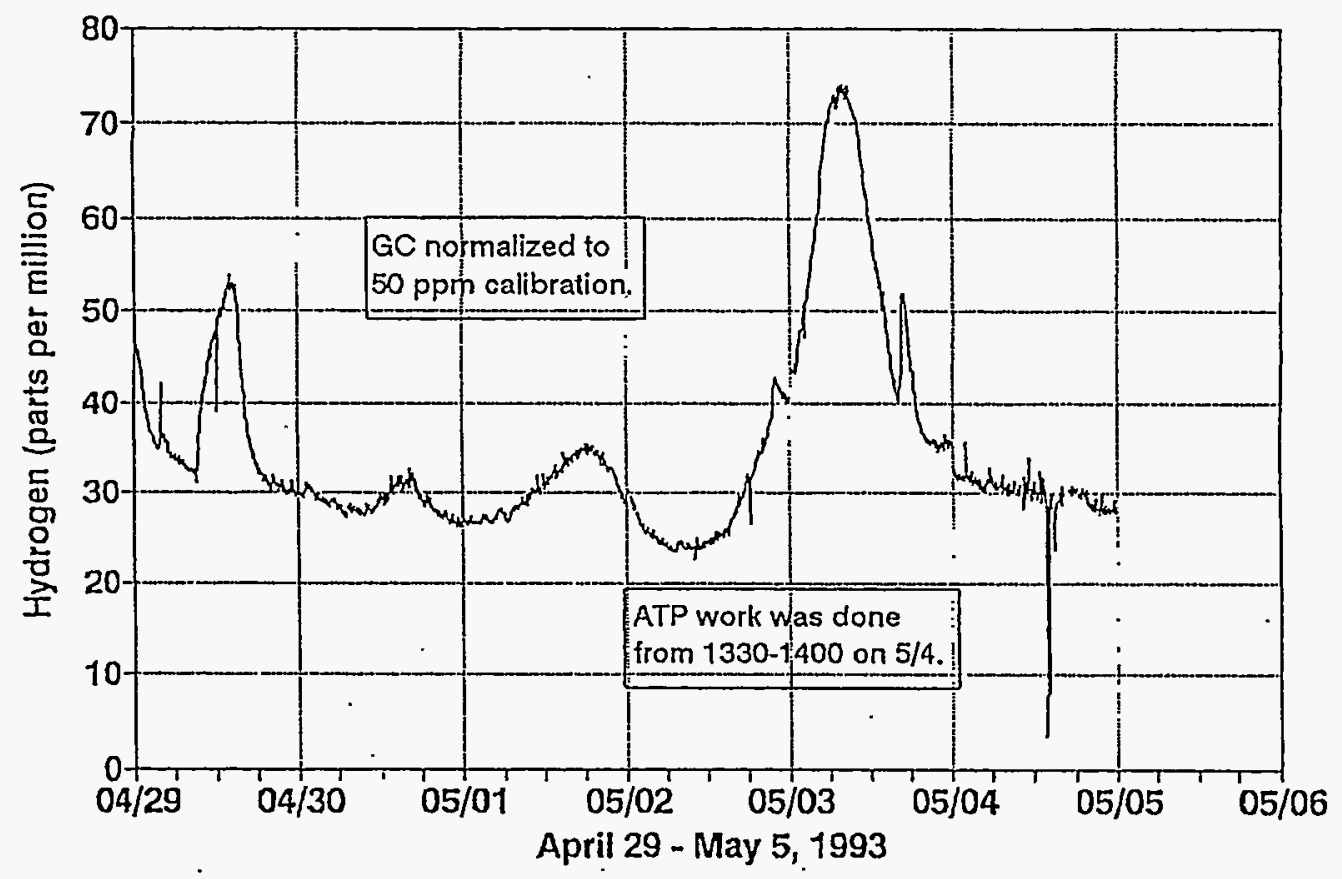

Figure 14b. Hydrogen Concentrations from April 29 to May 5, 1993 
increasing motion of the surface up and down by compression and expansion of the larger amounts of stored gas due to barometric pressure changes, or to the bulging upwards of the sludge layer as the gob approaches its stress limit. These speculations have not been quantified.

\section{Nitrous Oxide Solubility}

It has been noted that nitrous oxide is more soluble in water than hydrogen, and this has been suggested as an explanation for the changes in the reported gas ratios [Wise (1993) $)^{(\mathrm{a})}$ ]. In cold water, the solubility is about 20 times that of hydrogen (Allemann 1991). ${ }^{(b)}$ Bryan and Pederson (1992) ${ }^{(\mathrm{c})}$ measurements on synthetic waste gave values of nitrous oxide solubility in $50^{\circ} \mathrm{C}$ simulated waste of about $0.2 \mathrm{cc} / 100 \mathrm{~mL}$ versus about $0.5 \mathrm{cc} / 100 \mathrm{~mL}$ as estimated for hydrogen. Thus the solubilities of the gases are extremely low and may be on the same order of magnitude. The estimated saturation concentration of nitrous oxide in the waste sludge at $2 \mathrm{~atm}$ is then about $10^{-4}$ molar. This is about 30,000 times smaller than the calculated concentration of ammonia and would give negligible effects in coming out of solution relative to the ammonia. The changing ratio of ammonia to nitrous oxide with concentration may be an artifact of the instrument calibration. Wise (1993) indicates that there is discernable concentration/ratio effect even in the grab samples taken early in 1993 that were analyzed by mass spectrophotometer instead of the FTIR. However, the data are quite scattered at the low concentrations and some error (possibly systematic) may have resulted in the low concentration data that have to be specially corrected for the similar mass number of carbon dioxide (which is in much larger concentration). In addition, the mass spectrometer was not operating smoothly due to temperature control problems. On the other hand, it is certainly difficult to explain a measurable change in hydrogen/nitrous oxide ratio by physical processes in the tank.

(a) Wise, B. $M .1993$. "Changes in $\mathrm{H}_{2} / \mathrm{N}_{2}$ O Ratio During Small Releases" Memo to R. Allemann, June 16, 1993, Pacific Northwest Laboratory, Richland, Washington.

(b) Allemann, R. T. 1991. "Effect of $\mathrm{N}_{2} 0$ Solubility on Composition Measured for 101-SY Growth Gas," Letter to Dennis Strachan, September 24, 1991, Pacific Northwest Laboratory, Richland, Washington.

(c) Bryan, S. A., L. R. Pederson. 1992. "Solubility of Nitrous Oxide," Meeting Minutes, Tank Waste Science Panel, March 25-27, 1992, Pacific Northwest Laboratory, Richland, Washington. 


\section{Conclusions}

Three mechanisms of ammonia release from tank 241-SY-101 are proposed. These are quantified sufficiently to show that they can explain the major features of ammonia release phenomena observed, such as the changing ratios of ammonia to hydrogen in baseline versus GRE. The quantitative effect of barometric pressure on ammonia release rates is not fully explained here by the theory. Nitrous oxide is of low solubility in the waste and behaves similarly to hydrogen.

The mechanisms of ammonia release are as follows:

1. Bubble Transport accounts for about $6 \mathrm{ppm}$ of the basal ammonia rate and about $1 / 5$ the hydrogen concentration as ammonia in a major rollover.

2. Permeation diffusion accounts for about $40 \mathrm{ppm}$ release concentration ammonia during the quiescent periods in the tank.

3. Diffusion from wet liquid surface accounts for very high concentrations of (up to $1.3 \%$ ) observed in large GREs and for increased ammonia concentration due to water lancing or sluicein operations. The concentration of ammonia produced by this mechanism is proportional to the area of new wet surface created by the action in the tank.

The behavior of the tank waste suggests that ammonia release is moderated by the existing properties of the waste. A great deal of pumping effort would be required to change this characteristic. 
$$
\text { . }
$$ 


\section{References}

Bird, R. B., W. E. Stewart, E. N. Lightfoot. 1960. Transport Phenomena, John Wiley, New York.

Bolz, R. E., and G. L. Tuve, eds. 1970. Handbook of Tables for Applied Engineering Science. 2nd ed. The Chemical Rubber Company, Cleveland, Ohio.

Deepak, P. D, and S. K. Bhatia. 1994. "Transport Capillary Network Models of Porous Media: Theory and Simulation," Chemical Engineering Science, Vol. 49, No. 2, pp. 245-257.

Edwards, J. N. 1993. "A Safety Assessment for Proposed Pump Mixing Operations to Mitigate Episodic Gas Releases in Tank 241-SY-101: Hanford Site, Richland, Washington."

LA-UR-92-3196, Rev. 5, U.S. DOE Safety Assessment, October 8, 1993.

Fort, J. A., J. A. Bamberger, J. M. Bates, C. W. Enderlin, and M. R. Elmore. 1993. "1/12-Scale Physical Modeling Experiments in Support of Tank 241-SY-101 Hydrogen Mitigation." PNL-8476, Pacific Northwest Laboratory, Richland, Washington.

Gregg, S. L., and D. Brumblecombe. 1989. "Solubility or Ammonia in Pure Aqueous and Multicomponent Solutions." Reprint No. 022-3654/89/2093/7237. American Chemical Society, New York.

Harriott, P. 1964. Process Control. McGraw-Hill, New York.

Herting D. L., D. B. Bechtold, B. A. Crawford, T. L. Welsh, and L. Jenson. 1992. "Laboratory Characterization of Samples Taken in May 1991 from Hanford Waste Tank 241-SY-101," WHC-SD-DTR-024, Westinghouse Hanford Company, Richland, Washington, February, 1992.

Strachan, D. M. 1975. "Permeability, Capillarity, and Pore Volume of Synthetic Hanford Salt Cake," WHC-ARH-ST-129, Westinghouse Hanford Company, Richland, Washington, November 1975.

Trent, D. S. and T. E. Michener. 1993. "Numerical Simulation of Jet Mixing Concepts in Tank 241-SY-101." PNL-8559, Pacific Northwest Laboratory, Richland, Washington. 
Appendix A

Estimation of Ammonia Concentration 


\section{Appendix A}

\section{Estimation of Ammonia Concentration}

The ammonia concentration in the waste can be obtained from the vapor pressure data of ammonia over the waste salt solution if the partial pressure of ammonia is known and saturation equilibrium is assumed. Tank 241-SY-101 has been producing gas since it was filled about 14 years ago. If the liquid is not saturated with ammonia, then the concentration may still be growing and give a lower partial pressure of ammonia in the gas bubbles than does the saturation assumption. The calculation based on saturation will give a higher concentration of ammonia then would be the case if the liquid were unsaturated. Saturation equilibrium is presumed to exist in gas that is retained in the waste nonconvective layer at about 2 atm pressure. When hydrogen is released from this layer, the rate of hydrogen release (concentration in the steady off-gas flow) is increased. At the same time, there is an increase in the rate of ammonia release. If the release is small, as during a small pump bump or in the phase B series of tests wherein there is no waste motion observed, ${ }^{(a)}$ the third mechanism of ammonia release can be neglected because there is no creation of fresh liquid surface. Thus the size of increase in ammonia concentration immediately after a bump/small phase B test can be proportioned to the size of the hydrogen increase above its basal level to give the ratio of the two gases in the bubble transport mechanism of release. Relative differences in transport to and from the bubbles between the two gases is neglected because the time that the gas concentrations rise after a pump bump is short, only a few minutes, and the concentration external to the bubble are assumed to be constant in both layers.

Figure A.1 and A.2 show examples of the concentration rises during a period of pump bumping testing in December 1993, when no waste motion was observed.

Table A.1 shows the rough estimates of the concentration changes during some of these bumps and the ratios of the gas release caused by the postulated bubble transport mechanism.

Table A. 1 shows that the release of ammonia is about 1/5 that of the insoluble gas, hydrogen, and that the change in nitrous oxide concentrations are on the same order as that of hydrogen. The data giving a ratio of 2 in Table A.1 were taken when large changes in vent flow rate were being made and are therefore suspect. If the $1 / 5$ ratio is true for all of the bubbles that release from the tank, then it can be used to estimate the fraction of the gas that is ammonia. The bubble release gas consists of a mixture of hydrogen, nitrogen, nitrous oxide, ammonia, water, and other gases as listed by Reynolds (1993). ${ }^{(b)}$ Considering the accuracy of the estimates, the three main gases are assumed

(a) Although the camera does not view the entire surface (so that one might be sure that no waste motion occurred) the camera did record waste motion in some cases during bumping and phase B test where larger releases occurred. These are eliminated and the assumption made that small releases involved no surface motion.

(b) Reynolds, D. A. 1993. "Gas Composition of 101-SY from the June 1993 Event," Internal Memo to N. Kirch, 7E100-93-090, July 22, 1993, Westinghouse Hanford Company, Richland, Washington. 
Tank 241-SY-101

Gas Chromatograph 3 Hydrogen

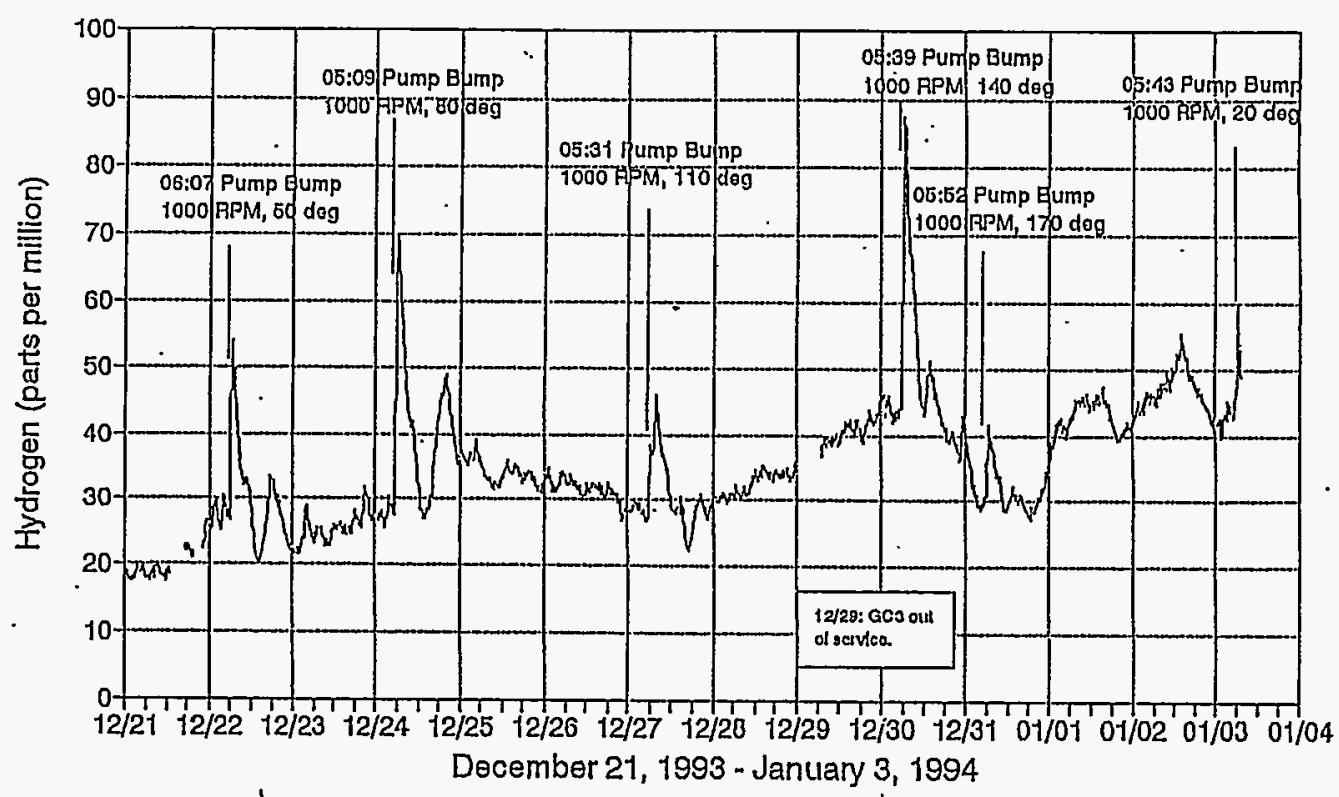

GC3 ls used tor hydrogen conoentratlons bolow $100 \mathrm{ppm}$.

Figure A.1. Hydrogen Concentrations from December 21, 1993 to January 3, 1994

Tank 241-SY-101

FTIR Gas Compositions

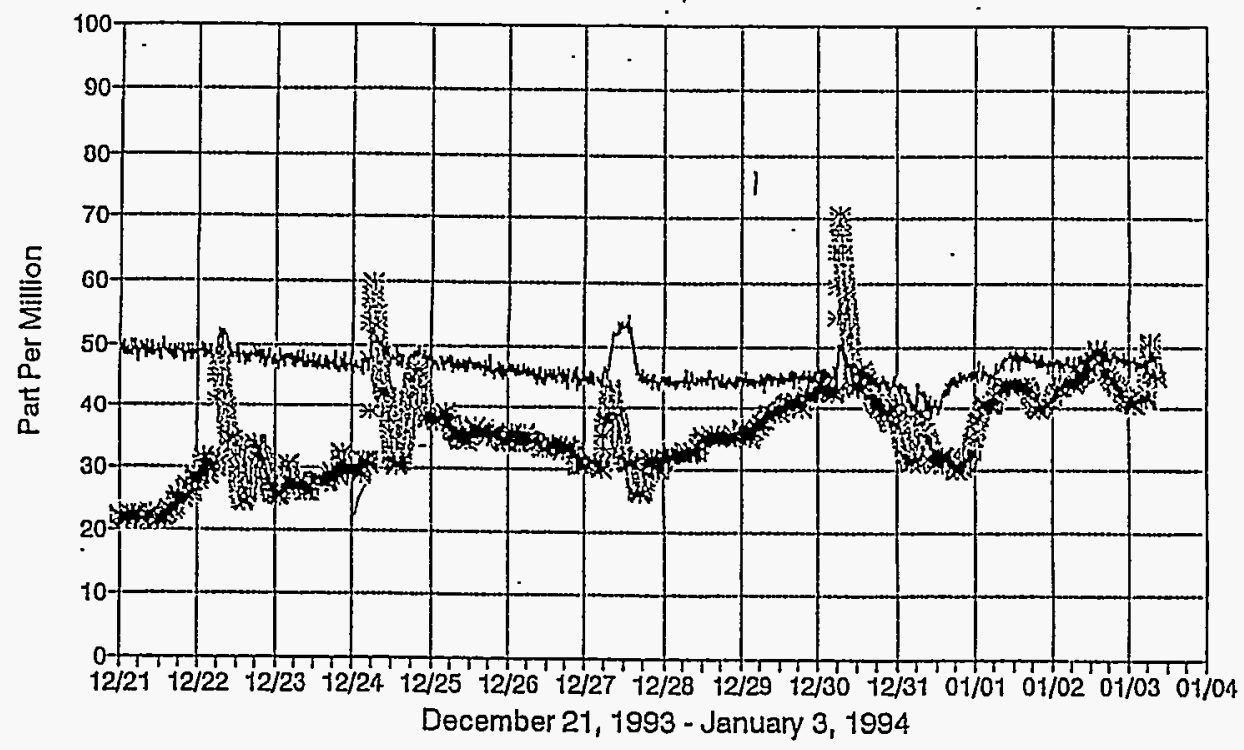

- $\mathrm{NH3}$ * $\mathrm{N} 2 \mathrm{O}$

Figure A.2. Ammonia and Nitrous Oxide Concentrations from December 21, 1993 to January 3, 1994 
Table A.1. Changes in Gas Concentration by Small Bumps

\begin{tabular}{|c|c|c|c|c|c|}
\hline $\begin{array}{c}\text { Date, Pump } \\
\text { Action } \\
\end{array}$ & $\begin{array}{c}\Delta \text { Conc. } \mathrm{H}_{2} \\
\text { ppm }\end{array}$ & $\begin{array}{c}\Delta \operatorname{ConcN}_{2} \mathrm{O} \\
\mathrm{ppm} \\
\end{array}$ & $\begin{array}{c}\Delta \mathrm{ConcNH}_{3} \\
\mathrm{ppm}\end{array}$ & $\Delta \mathrm{H}_{2} / \Delta \mathrm{NH}_{3}$ & Comment \\
\hline $\begin{array}{l}12 / 15 / 93 \\
920,35^{\circ}\end{array}$ & 100 & 70 & 28 & 4 & \\
\hline $\begin{array}{l}12 / 17 / 93 \\
920,95^{\circ}\end{array}$ & 130 & 100 & 40 & 4.2 & \\
\hline $\begin{array}{l}12 / 22 / 93 \\
\text { bump, } 50^{\circ}\end{array}$ & 25 & 18 & 5 & 5 & \\
\hline $\begin{array}{l}12 / 24 / 93 \\
\text { bump, } 80^{\circ}\end{array}$ & 43 & 27 & 5 & 8 & \\
\hline $\begin{array}{l}12 / 27 / 93 \\
\text { bump, } 110^{\circ}\end{array}$ & 18 & 12 & 8 & 2 & Flow rate change \\
\hline $\begin{array}{l}12 / 30 / 93 \\
\text { bump, } 140^{\circ}\end{array}$ & 42 & 28 & 5 & 8 & \\
\hline $\begin{array}{l}12 / 31 / 93 \\
\text { bump, } 110^{\circ}\end{array}$ & 12 & 10 & 5 & 2 & Flow rate change \\
\hline $\begin{array}{l}01 / 03 / 94 \\
\text { bump, } 20^{\circ}\end{array}$ & 15 & 12 & 3 & 5 & \\
\hline
\end{tabular}

Table A.2. Summary of Bubble Release Gas Composition

\begin{tabular}{lcc}
\multicolumn{1}{c}{ Gas } & & $\%$ \\
\cline { 1 - 1 } Hydrogen & & 30.6 \\
Nitrous Oxide & & 30.6 \\
Nitrogen & & 30.6 \\
Ammonia & & 6. \\
Water Vapor & & 2 \\
Other & & $<1$.
\end{tabular}

to have the same concentration, roughly $30 \%$ of the volume each. Then, with nitrous oxide as $1 / 5$ of the hydrogen, or $6 \%$, and including a water content of about $2 \%$ as estimated by Allemann $(1992),{ }^{(a)}$ the estimated gas composition of the growth gas is as shown in Table A.2.

If the gases that are released by the bubble mechanism have come from deep in the tank, the pressure would be approximately $2.1 \mathrm{~atm}$. Then the ammonia partial pressure would be $0.06 \times 2.1=$ $0.126 \mathrm{~atm}=95.7 \mathrm{~mm} \mathrm{Hg}$. Using the vapor pressure equilibrium line in Allemann (1993), ${ }^{(b)}$ the

(a) Allemann, R. T. 1992a. "Water Vapor in Slurry Growth Gas," Letter to Max Kreiter, June.6, 1992, Pacific Northwest Laboratory, Richland, Washington.

(b) Allemann, R. T. 1993. "Effect of Dissolved Ammonia on Void Fraction: Determination by In Situ Sample Compression," Letter Report, Flammable Gas Safety Program, PNL-FGP121394, November 30, 1993, Pacific Northwest Laboratory, Richland, Washington. 
saturated concentration of ammonia is $3 \%$ (using the $140^{\circ} \mathrm{F}$ line which represents the warm salt solution in the tank) at this hydrostatic pressure. Most of the tank is at less pressure so this value is conservatively high. This is estimated to be about 2.6 molar ammonia concentration which is higher than the concentration that might result from the total conversion of organic amine groups to ammonia. Thus it is likely that some of the ammonia is coming from reduction of the nitrogen-containing salt ions. Also W. Kubic of LANL (Gregg 1989) has brought to attention some additional data and a method of calculating the vapor pressure of ammonia in strong salt solutions. This method will give higher vapor pressures than estimated above and will reduce the equilibrium concentration of ammonia in the waste by a factor of 3 to 5 . This would give an ammonia concentration in the waste of .6 to $1 \mathrm{wt} \%$. 


\section{Appendix B}

\section{Permeation of Ammonia Through Crust Layer}




\section{Appendix B}

\section{Permeation of Ammonia Through Crust Layer}

The ammonia concentration data from January 1994 indicate that the basal rate of ammonia coming off the quiescent tank 241-SY-101 is about $45 \mathrm{ppm}$. Nitrous oxide and hydrogen have decreased to about $30 \mathrm{ppm}$. Assuming that the ammonia release rate due to the bubble transport mechanism is about $1 / 5$ that of hydrogen (about $6 \mathrm{ppm}$ ), a release of approximately $40 \mathrm{ppm}$ occurs as a result of the second mechanism, that of diffusion from the dissolved ammonia in the liquid, i.e., permeation through the upper layers.

The temperature profiles from late 1993 and early 1994 show a layer of low thermal conductivity in the upper 100 in: of the waste. The 17B thermocouple tree indicates a 40 in. crust and a 60 in. transition region below it. The 17C shows the steep temperature drop in going from 300 to 400 in. Below these is a constant temperature "convective" or mixed layer, which is assumed to be uniform in concentration of dissolved ammonia at $3 \mathrm{wt} \%$ (2.6 molar). This concentration was estimated in - Appendix A and would give a vapor pressure of $80-95 \mathrm{~mm} \mathrm{Hg}(0.105-0.125 \mathrm{~atm})$, according to the vapor pressure correlations in Allemann (1993).

The measured concentration of ammonia in the dome space or vent is $45 \mathrm{ppm}$, giving a partial pressure of about $45 \mathrm{E}-6 \mathrm{~atm}$. The driving force for ammonia mass transport then is essentially equal to the ammonia vapor pressure $(0.11 \mathrm{~atm})$ in solution.

Because the ammonia is coming through the crust at a greater rate than hydrogen and nitrous oxide are, and at a rate different from that calculated for the flow associated with bubble transport, some of the ammonia transport is independent of the transport of the other two gases.

Consider the ammonia transport on the basis of permeability. A Darcy transport equation (Bird et al. 1966) is

$$
\mathrm{u}=\frac{-\mathrm{k}}{\mu} \frac{\mathrm{dP}}{\mathrm{dL}}
$$

where

$$
\begin{aligned}
\mathrm{u} & =\text { flux of material, } \mathrm{cm} / \mathrm{sec} \\
\mathrm{k} & =\text { permeability, Darcy } \\
\mu & =\text { viscosity, } \mathrm{cP} \\
\mathrm{dP} / \mathrm{dL} & =\text { pressure gradient, } \mathrm{atm} / \mathrm{cm}
\end{aligned}
$$

The value of permeability for the upper layer can be estimated for diffusion of ammonia across the entire surface of the tank. 
When

$$
\mathrm{u}=\frac{\dot{V}}{\mathrm{~A}}=\frac{(40 \mathrm{E}-6) \times 520 \frac{\mathrm{ft}^{3}}{\mathrm{~min}} \times \frac{1}{60} \frac{\mathrm{min}}{\mathrm{sec}} \times(30.48)^{3} \frac{\mathrm{cm}^{3}}{\mathrm{ft}^{3}}}{4418 \mathrm{ft}^{3} \times(30.48)^{2} \frac{\mathrm{cm}^{2}}{\mathrm{ft}^{2}}}=2.4 \mathrm{E}-6 \frac{\mathrm{cm}}{\mathrm{sec}}
$$

then

$$
\frac{\mathrm{dP}}{\mathrm{dL}}=\frac{0.11}{100 \times 2.54}=4.3 \mathrm{E}-4 \frac{\mathrm{atm}}{\mathrm{cm}}
$$

Typical values of viscosity are obtained from CRC Handbook (1970):

Viscosities of Gases

\begin{tabular}{ll}
\multicolumn{1}{c}{ Gas } & Viscosity, cP \\
Ammonia & 0.01 \\
Air & 0.018 \\
Nitrous Oxide & 0.015 \\
Nitrogen & 0.018 \\
Hydrogen & 0.009
\end{tabular}

Using a viscosity value for ammonia, the permeability can be calculated as

$$
k=2.4 \mathrm{E}-6 \times \frac{0.01}{4.3 \mathrm{E}-4}=5.6 \mathrm{E}-5 \text { Darcy }
$$

This is much lower than the 1 Darcy range of values that Strachan (1975) measured for packed synthetic salt cake. Thus a packed salt cake model would not be adequate for describing the crust/foam layer in tank 241-SY-101.

If the diffusion rate were limited by a $100 \mathrm{in}$. stagnant gas layer on the top of the waste, then the steady-state flux of the gas would be given by the equation as given in Bird et al. (1960):

where

$$
\mathrm{j}=\frac{\mathrm{c} \mathrm{D}_{\mathrm{M}}}{\Delta \mathrm{Z}} \ln \left[\frac{1-\mathrm{X}_{\mathrm{A}, 2}}{1-\mathrm{X}_{\mathrm{A}, 1}}\right]
$$

$$
\begin{aligned}
\mathrm{j} & =\text { molar flux, moles/ } \mathrm{L}^{2} \mathrm{~T} \\
\mathrm{D}_{\mathrm{m}} & =\text { molecular diffusivity, } \mathrm{L}^{2} / \mathrm{T} \\
\Delta \mathrm{Z} & =\text { thickness of layer, } \mathrm{L}
\end{aligned}
$$

$\mathrm{X}_{\mathrm{A}, 1} ; \mathrm{X}_{\mathrm{A}, 2}=$ molar fractions of ammonia at the bottom and top of layer. 
Define a diffusion flux velocity, $\mathrm{U}_{\mathrm{D}_{\mathrm{M}}}$ :

$$
\mathrm{U}_{\mathrm{D}_{\mathrm{M}}}=\frac{\mathrm{j}}{\mathrm{c}}=\frac{\mathrm{D}_{\mathrm{M}}}{\Delta \mathrm{Z}} \ln \left[\frac{1-\mathrm{X}_{\mathrm{A}, 2}}{1-\mathrm{X}_{\mathrm{A}, 1}}\right]
$$

Tables of diffusivity in Bird et al. (1960) give typical values of $0.15 \mathrm{~cm}^{2} / \mathrm{sec}$, which when adjusted to $50^{\circ} \mathrm{C}$ are about $0.19 \mathrm{~cm}^{2} / \mathrm{sec}$.

Assuming the molar fraction at the top of the layer is negligible, an estimate of the diffusion flux velocity through the stagnant gas is

$$
U_{D_{\mu}}=\frac{0.19 \frac{\mathrm{cm}^{2}}{\mathrm{sec}}}{254 \mathrm{~cm}} \ln \left[\frac{1}{1-0.11}\right]=8.7 \mathrm{E}-5
$$

Using the experimental flux estimated above, the ratio of the mass transport to the molecular diffusivity is

$$
\mathrm{k}^{*}=\frac{\mathrm{k}_{\mathrm{e}}}{\mathrm{D}_{\mathrm{M}}}=\frac{\mathrm{u}}{\mathrm{u}_{\mathrm{D}_{\mathrm{M}}}}=\frac{2.43 \mathrm{E}-6}{8.7 \mathrm{E}-5}=3 \mathrm{E}-2
$$

where $k_{e}=$ effective diffusivity. Thus the effective diffusivity is on the order of 0.03 times molecular diffusivity.

This lower effective diffusivity can be explained by the effect of the diffusion through the foam and crust layer. For example, Deepak and Bhatia (1994) give values of $\mathrm{k}^{*}$ ranging from $10^{-3}$ to $10^{-2}$ for a discrete bimodal pore size model over a range of porosity ratios $(0.005$ to 50$)$. Thus it is quite likely that the reduced value needed to account for the calculated flux would be explained by the porous media theory. The actual (fairly slow) rate of ammonia transport through the foam/crust could be the result of the pore network effects even when the crust is somewhat dry.

If the upper layer near the surface is actually a foam (in which the gas bubbles are separated by lamellae) with thin walls between the bubbles rather than interconnected pores, a different theory would have to be invoked to consider the gas transport from bubble to bubble across the membranes. The literature was not explored fully enough to demonstrate the transport coefficient range that might result, but it would surely be low also. 
Appendix C

\section{Diffusion of Ammonia from Fresh Liquid Surface}




\section{Appendix C}

\section{Diffusion of Ammonia from Fresh Liquid Surface}

With a large rollover, there is an exposure of new surface that appears to be wet and which is associated with an extra large amount of ammonia in the dome (vent gas) that trails off at a slower rate than the hydrogen and nitrous oxide concentrations. Figure C. 1 shows the nitrous oxide and ammonia concentrations in the vent/dome space of the 241-SY-101 following the August 27, 1993, gas release event (which was accompanied by a 2 " surface level drop) and subsequent period of pump bumping. The ammonia concentration increased to an extremely high level following the event and then returned only slowly toward the basal level relative to the "insoluble." nitrous oxide. The nitrous oxide concentration decay can be seen to consist of a relatively fast drop off with each peak on top of a slower decay that is believed to be the result of a decaying rate of bubble release from the overturned material. This slower decay rate is consistent with the bubble-rise mechanism described by Allemann (1992a). ${ }^{\text {(a) }}$ The mini-release event of August 27, 1993, had a long-term decay half time of two or three days onto which were superimposed releases by additional bump releases.

The rate of decay of a concentration pulse into the dome space is an important parameter in understanding the behavior of the gas in question. Different mechanisms contribute to the rate of decay measured. For a single pulse of gas release to the dome space, the concentration decays away exponentially and is similar to a simple mixed vessel. Figure C.1 shows a numerical model of the concentration of a gas in the dome space of 241-SY-101 (Eyler 1993). ${ }^{(b)}$ It can be seen that the exit concentration of a short pulse addition of gas decays away exponentially, no matter where the gas was input from the waste surface. This implies that the dome space is well mixed, an assumption very important to simplifying the analysis of the gas release mechanisms. The time constant for the dome space is 65 to $70 \mathrm{~min}^{-1}$ as deduced from the Eyler computer results. The time constant of a mixed vessel applied to the vented dome space (volume/flow rate) is about $60 \mathrm{~min}^{-1}$ and is in basic agreement with the Eyler calculation.

Therefore, if the time constant of concentration decay differs significantly from dome space time constant, it may be deduced that the input is not a short pulse but may instead be following a decay pattern of its own. If this pattern is long relative to the dome space decay, its time constant may also be deduced.

For the event of August 27,1993 (see Figure C.2), the hydrogen peaked at approximately $7000 \mathrm{ppm}$ and then decayed away with a time constant of about $114 \mathrm{~min}^{-1}$. About $1 / 5$ of this then is $1400 \mathrm{ppm}$ of the ammonia concentration that would be associated with the hydrogen bubble release of mechanism 1. The ammonia peak for this event was $1.3 \%$, or $13,000 \mathrm{ppm}$, leaving $11,600 \mathrm{ppm}$

(a) Allemann, R. T. 1992. Physical Mechanisms Contributing to the Episodic Gas Release from Hanford Tank 241-SY-101, International High Level Radioactive Waste Conference, Las Vegas, Nevada, April, 1992.

(b) Eyler, L. L. 1993. 3D Computer Modeling of SY-101 Dome Space Mixing, Letter to Walter Knecht/WHC, December 6, 1993, ASD-93-005, Analytic Sciences Department, Pacific Northwest Laboratory, Richland, Washington. 


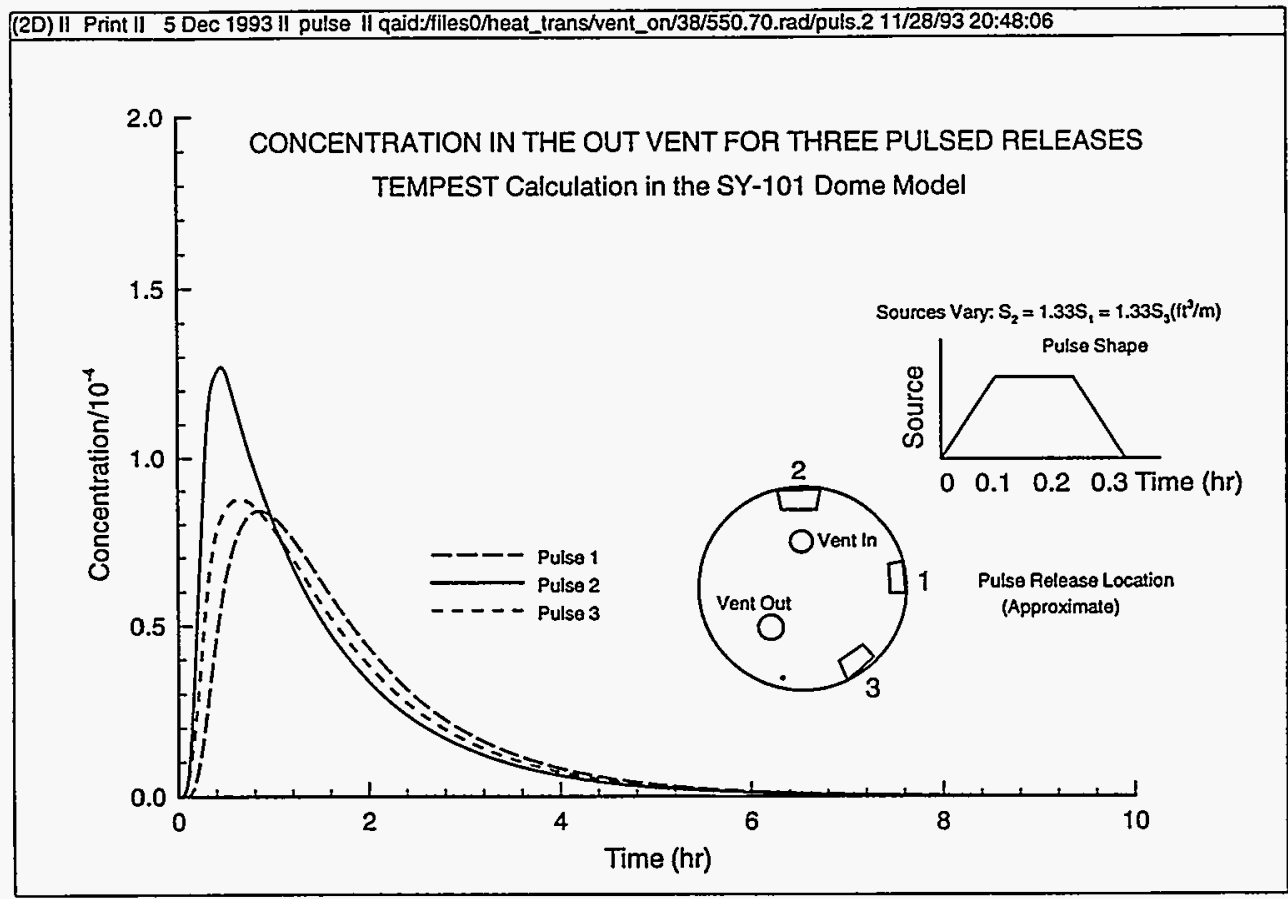

Figure C.1. Time-dependent Concentration in the Outlet Vent for Three Pulsed Release Cases with Ventilation Temperature of $70^{\circ} \mathrm{F}$ (from Eyler 1993)

Tank 241-SY-101

FTIR Gas Compositions

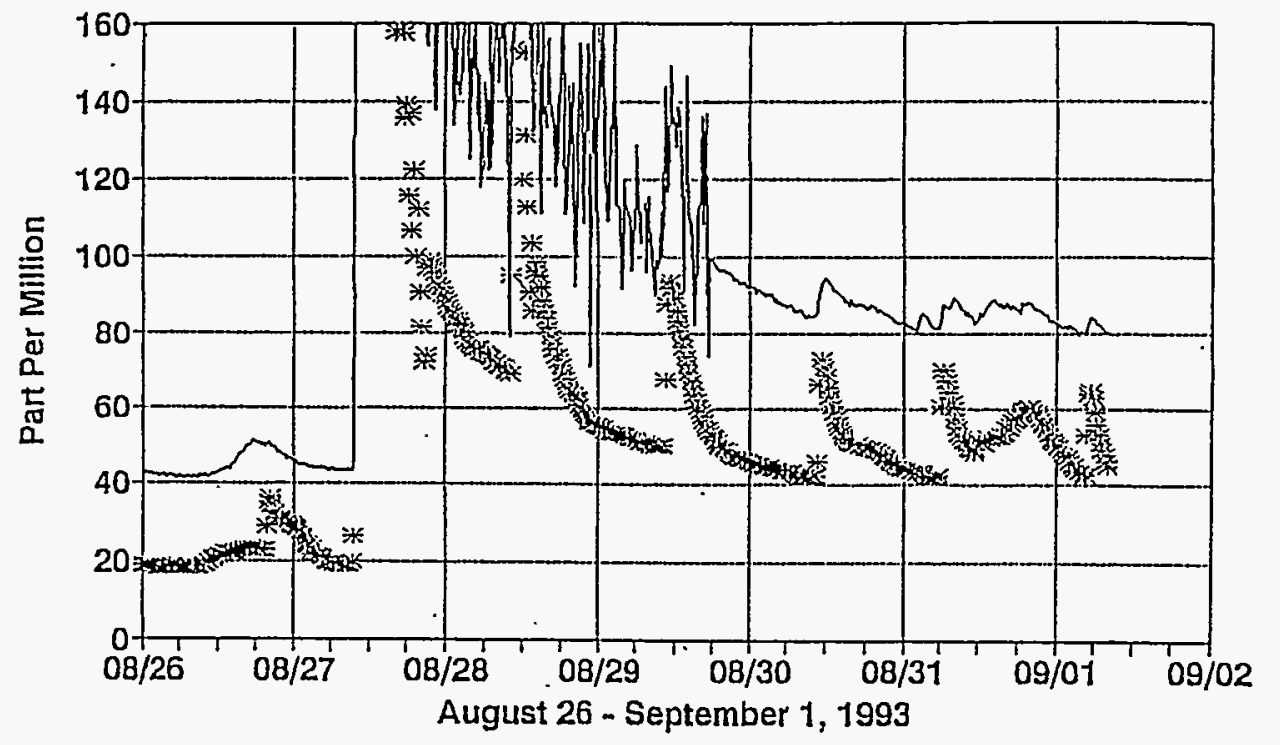

- $\mathrm{NH3}$ \% $\mathrm{N} 2 \mathrm{O}$

Figure C.2. Ammonia and Nitrous Oxide Concentrations from August 26 to September 1, 1993 
being associated with the suggested mechanism 3, the direct diffusion of ammonia from newly created wet liquid surface. The videos of the August 27 event showed liquid motion over perhaps an estimated one quarter of the waste surface.

The ammonia concentration decreased with a half time of about $4.4 \mathrm{hrs}$ giving a time constant of $380 \mathrm{~min}^{-1}$. If the concentration decays away exponentially, one can estimate the initial amount added to a mixing vessel (or chamber) by a simple integration of the concentration times the flow rate. The total volume is

$$
\text { Volume }=\int_{0}^{t} F \times C d t=F C_{0} \int_{0}^{t} e^{-\lambda t} d t
$$

where

$$
\begin{aligned}
\mathrm{F} & =\text { flowrate } \\
\mathrm{C} & =\text { concentration } \\
\lambda & =\text { time constant } \\
\mathrm{t} & =\text { time }
\end{aligned}
$$

Integrating this becomes

$$
\text { Volume }=\frac{F C_{0}}{-\lambda}\left[e^{-\lambda}\right]_{0}^{\infty}
$$

and

$$
\text { Volume }=\frac{\mathrm{FC}_{0}}{\lambda}=550 \times 11400 \mathrm{E}-6 \times 380=2,400 \mathrm{ft}^{3}
$$

of ammonia released. This is about

$$
\frac{2,400 \times 28.3}{22.4} \simeq 3,000 \mathrm{~g} \text {-moles of ammonia. }
$$

If the new liquid at the surface is 2.6 molar and assuming no solids, then in forming a diffusion boundary layer the average concentration would be reduced by a factor of about one half, losing 1.3 moles/L.

If one fourth of the tank area was given a fresh liquid surface that stagnated, the depth of the B.L. to produce 3,000 moles would be

$$
\delta=\frac{3,000}{\frac{1.3 \mathrm{moles}}{1,000 \mathrm{~cm}^{3}} \times .25 \times 4418 \times(30.48)^{2}}=2.2 \mathrm{~cm}
$$


Consider the release of ammonia to be two first order processes in series. The first is the release to the dome space with a decay constant, ${ }^{(a)} \lambda_{1}$, and the release to the vent and mixing in the dome space with decay constant, $\lambda_{2}$. The combined step response of two non-interacting system time constants in series is about 0.73 at time t (Harriott 1964, p.48), where

$$
\frac{t}{\frac{1}{\lambda_{1}}+\frac{1}{\lambda_{2}}}=1.3
$$

The $73 \%$ response time of the ammonia is obtained from its estimated time constant of $380 \mathrm{~min}^{1}$ by solving

$$
(1-0.73)=e^{-\frac{t}{380}}
$$

The resulting time constant is 499 minutes.

Then $\lambda_{1}$ can be found from

$$
\frac{499}{\frac{1}{\lambda_{1}}+65}=1.3
$$

and

$$
\frac{1}{\lambda_{1}}=319 \min
$$

This gives is the time constant for the diffusion of the ammonia out of the exposed liquid surface into the dome space. If the transport is considered to be by molecular diffusion through a stagnant liquid medium, the thickness of the developing boundary layer can be estimated.

A typical diffusivity $\left(\mathrm{D}_{\mathrm{M}}\right)$ of ammonia in a liquid is about $2 \mathrm{E}-5 \mathrm{~cm}^{2} / \mathrm{sec}$. Harriott $(1964, \mathrm{p} .351)$ gives the time response to $63 \%$ depth of a diffusive liquid boundary layer as

$$
t_{63}=\frac{z^{2}}{2} D_{M}
$$

then for the boundary layer

(a) This is an approximation. The decay of concentration for a boundary layers a power function. For simplicity, it is taken as an exponential. 


$$
(1-0.63)=e^{-\frac{t_{b}}{319}} \text { and } t_{63}=317 \mathrm{~min}
$$

thus,

$$
\mathrm{Z}=\sqrt{2 \mathrm{D}_{\mathrm{M}} \mathrm{t}_{63}}=\sqrt{2 \times 2 \mathrm{E}-5 \times 317 \times 60} \simeq 1 \mathrm{~cm}
$$

Thus the order-of-magnitude estimate of the depth of the boundary layer limited by diffusion in the liquid is of the same order of size as the depth $(2 \mathrm{~cm})$ calculated above based on the estimated liquid area and amount of ammonia released in a large GRE. Several values in these estimates can be adjusted to bring better agreement. The area of the new liquid surface is a gross estimate. Larger areas would give a smaller concentration boundary layer as would an assumption of some convection in the fresh liquid. This would bring the amount based boundary layer closer to the diffusion based boundary thickness. 


\section{DISTRIBUTION}

No. of

Copies

OFFSITE

12 DOE/Office of Scientific and Technical Information

\section{S. Agnew}

Los Alamos National Laboratory

MS-C345, Group INC-4

P.0. Box 1664

Los Alamos, NM 87545

N. E. Bibler

Westinghouse Savannah River

Bldg. 773A, Room 108

Aiken, SC 29802

K. Pasamehmetoglu

Los Alamos National Laboratory

P.0. Box 1663

MS $-K 555$

Los Alamos, NM 87545

B. C. Huds on

202 Northridge Port

Lindsborg, KS 67456

L. Kovach

NUCON

P.0. Box 29246

Columbus, OH 43229

D. Pepson

U.S. Department of Energy

EM 36/Trevion II

Washington, DC 20585-0002

W. W. Schulz

727 Sweetleaf Drive

Wilmington, DE 19808
No. of

Copies

ONSITE

3 DOE Richland Operations Office

$\begin{array}{ll}\text { R. F. Christensen } & \$ 7-54 \\ \text { G. Rosenwald } & \text { S7 }-54 \\ \text { Reading Room } & \mathrm{A} 1-65\end{array}$

17 Westinghouse Hanford Company

H. Babad

S7 -30

J. D. Hopkins

J. Jewett

G. D. Johnson (5)

R2-11

N. W. Kirch

T6-09

J. W. Lentsch

S7-15

N. G. McDuffie

R2-11

D. M. Ogden

S7-15

S7 -15

M. A. Payne

HO -34

D. A. Reynolds

S7 -14

D. J. Sherwood

R2 -11

S7 -15

D. A. Turner

S7 -15

R. J. Van Vleet

H4-63

39 Pacific Northwest Laboratory
R. T. Allemann
K $7-15$
W. J. Apley
S7 -71
Z. I. Antoniak
K7 -15
R. M. Bean
P8-08
S. Q. Bennett
J. W. Brothers (5)
K7 -90
S. A. Bryan
$K 5-22$
P7 -35
J. A. Campbe11
P8-08
J. B. Colson
$\mathrm{K} 5-10$
J. D. Hudson (10)
$\mathrm{K} 7-15$
P. A. Gauglitz
P7-41
S. C. Goheen
P8-08
B. M. Johnson, Jr.
K1-78
L. R. Pederson
K2-44
G. F. Schiefelbein
P8-38 
PNL-10091

UC-2030

No. of

Copies

ONSITE (continued)
L. A. Schienbein
$\mathrm{K} 5-20$
C. W. Stewart
K7 -15
D. M. Strachan
$\mathrm{K} 2-44$
D. S. Trent
$\mathrm{K} 7-15$
B. M. Wise
$\mathrm{K} 2-12$
Publishing Coordination
Technical Report Files
(5)
K1-06 